\title{
Impact of spatial resolution on the modelling of the Greenland ice sheet surface mass balance between 1990-2010, using the regional climate model MAR
}

\author{
B. Franco, X. Fettweis, C. Lang, and M. Erpicum \\ Département de Géographie, Université de Liège, Liège, Belgium \\ Correspondence to: B. Franco (bruno.branco@ulg.ac.be)
}

Received: 30 January 2012 - Published in The Cryosphere Discuss.: 13 February 2012

Revised: 4 June 2012 - Accepted: 5 June 2012 - Published: 27 June 2012

\begin{abstract}
With the aim to force an ice dynamical model, the Greenland ice sheet (GrIS) surface mass balance (SMB) was modelled at different spatial resolutions $(15-50 \mathrm{~km})$ for the period 1990-2010, using the regional climate model MAR (Modèle Atmosphérique Régional) forced by the ERAINTERIM reanalysis. This comparison revealed that (i) the inter-annual variability of the SMB components is consistent within the different spatial resolutions investigated, (ii) the MAR model simulates heavier precipitation on average over the GrIS with decreasing spatial resolution, and (iii) the SMB components (except precipitation) can be derived from a simulation at lower resolution with an "intelligent" interpolation. This interpolation can also be used to approximate the SMB components over another topography/ice sheet mask of the GrIS. These results are important for the forcing of an ice dynamical model needed to enable future projections of the GrIS contribution to sea level rise over the coming centuries.
\end{abstract}

\section{Introduction}

Meltwater run-off from the Greenland ice sheet (GrIS) has increased significantly during the past two decades, as highlighted by model simulations (Van den Broeke et al., 2009; Box et al., 2010; Tedesco et al., 2011) and satellite-based observations (Hall et al., 2008; Tedesco et al., 2008; Wouters et al., 2008), as a consequence of atmospheric warming over the Arctic (Box and Cohen, 2006; Hanna et al., 2008). Furthermore, recent studies have highlighted an important interannual variability in GrIS mass balance during the past several years (Howat et al., 2008; Wouters et al., 2008; Van den
Broeke et al., 2009). For example, high summer temperatures in 2007, 2008 and 2010 in Greenland (Tedesco et al., 2008, 2011) led to record GrIS melting and surface mass loss. A future warmer climate will induce a strengthened freshwater flux exceeding an increase in precipitation rate, consequently the GrIS is expected to accelerate its mass loss (Lemke et al., 2007) and to contribute substantially to the global sea level rise (SLR) (Meehl et al., 2007).

As suggested by Hanna et al. (2005) and Box et al. (2006), numerical models represent an opportunity to efficiently simulate the current GrIS surface mass balance evolution over long periods, given the gap in time and space of measurements in the field that causes large uncertainties in the related studies. Because of their sophisticated atmospheric physics and surface schemes parameterised for polar regions, regional climate models (RCMs) are often used to produce high-resolution GrIS surface mass balance (SMB) outputs with great success and reliability (e.g. Dethloff et al., 2002; Mote, 2003; Box et al., 2006; Ettema et al., 2009; Fettweis et al., 2011a).

The regional climate model MAR (Modèle Atmosphérique Régional) running at a resolution of $25 \mathrm{~km}$ has been used with demonstrable success to simulate the GrIS SMB since 1958 (Fettweis, 2007; Fettweis et al., 2011a; Lefebre et al., 2005), and through the 20th and 21st centuries (Fettweis et al., 2011b). Moreover, this RCM has been satisfactorily compared to passive microwave-derived observations (Fettweis et al., 2005, 2007, 2011a).

As a part of the ICE2SEA project (http://www.ice2sea. eu/policy/objectives), the $25 \mathrm{~km}$ resolution SMB outputs of the MAR model are required as forcing fields in ice sheet 
models in order to produce future projections of the GrIS contribution to SLR over the next $200 \mathrm{yr}$. Indeed, RCMs are usually designed to produce reliable SMB outputs as opposed to global models, from which SMB fields are generally deduced from temperature and precipitation fields separately (e.g. Huybrechts, 1994; Ritz et al., 1997; Van de Wal, 1999) or extracted by downscaling techniques (e.g. Robinson et al., 2010; Vizcaíno et al., 2010). Although the current spatial resolution of the MAR model $(25 \mathrm{~km})$ is much higher than the general circulation models (GCMs) resolution (150$300 \mathrm{~km}$ ), ice dynamical models are often run at a higher resolution (typically $5-10 \mathrm{~km}$ ). Such higher-resolution simulations with the MAR model, on the same integration domain, require a significant additional computing time compared to the $25 \mathrm{~km}$ resolution MAR simulations. In addition, the topography of the ice dynamical models varies and the SMB outputs from RCM cannot be directly transferred into the ice sheet models without topography-based corrections. This is because the ice sheet-tundra masks at different spatial resolutions do not match and the SMB is a complex function of spatial resolution and Greenland topography. Therefore enhanced methods of spatial interpolation are needed to use the $25 \mathrm{~km}$ resolution SMB outputs in ice dynamical models.

In this study, GrIS SMB outputs simulated by the MAR model at different spatial resolutions $(20,25$, etc. up to $50 \mathrm{~km}$ ) were compared with $15 \mathrm{~km}$ resolution MAR results. By gauging comparative anomalies, this work aims to assess the lack of accuracy generated when linearly interpolating SMB outputs from MAR onto a higher-resolution grid, compared to results of MAR running at this higher resolution. This analysis formed a necessary step before claiming the use of interpolated outputs to be suitable as forcing fields for an ice sheet model. Moreover, this type of experiment enabled the investigation of the impact of different spatial resolutions on the SMB simulated by MAR. Indeed, conflicting model behaviours related to the amount of simulated precipitation over Greenland have already been observed between RACMO (Ettema et al., 2009) and HadRM3 (J. L. Bamber and C. Vernon, personal communication, 2011) with decreasing spatial resolution of the RCM. In order to improve the comparison between the interpolated MAR results and the $15 \mathrm{~km}$ resolution MAR outputs, this study includes an enhanced SMB interpolation based on daily vertical gradients of the investigated field in the vicinity of each grid point. In addition, this interpolation can be used to correct the SMB components (except precipitation) for another GrIS topography/ice sheet mask.

A brief description of the MAR model and its set-up is given in Sect. 2. The validation of the MAR simulation at different spatial resolutions along the $\mathrm{K}$-transect is presented in Sect. 3. Section 4 is devoted to the assessment of the MAR outputs interpolated onto a higher-resolution grid, compared to the results of the MAR model running at this higher resolution. In Sect. 5, the impacts of an expanded integration domain on the MAR simulations are investigated. An enhanced
SMB interpolation and its related results are developed in Sect. 6. Finally, Sect. 7 details a MAR simulation performed with a coarse topography, and is followed by the discussion and conclusion of this study.

\section{The MAR model}

The RCM used in this study was the MAR (Modèle Atmosphérique Régional) model, described by Fettweis (2007), and whose atmospheric part is detailed in Gallée and Schayes (1994). The MAR model is fully coupled with an energy balance-based snow model allowing feedbacks between the surface and the atmosphere: the SISVAT scheme (Soil Ice Snow Vegetation Atmosphere Transfer) explained in De Ridder and Gallée (1998), Gallée et al. (2001) and Lefebre et al. (2003). The snow-ice part of SISVAT is a vertical onedimensional multi-layered energy balance model, consisting of a thermodynamic module, a turbulence module, an integrated surface albedo module, a water balance module taking into account meltwater refreezing, a snow/ice discretionary module, and a snow metamorphism module. Based on the CEN (Centre d'Etudes de la Neige) snow model called CROCUS (Brun et al., 1992), the SISVAT scheme works out the exchanges between the ice sheet surface, the snow-covered tundra, the sea ice and the atmosphere.

The MAR model is forced at the boundaries every $6 \mathrm{~h}$ by the ERA-INTERIM reanalysis. In this study, we used the same version as Fettweis et al. (2011a), whose radiative and snow model has been improved to reduce the simulated bias in melt highlighted by Fettweis et al. (2008). The Greenland topography used for our simulations was derived from the high-resolution $(5 \mathrm{~km})$ digital elevation model implemented by Bamber et al. (2001a,b) from radar altimetry, and the ice sheet mask is based on the Greenland land surface classification mask from Jason Box (http://bprc.osu. edu/wiki/Jason_Box_Datasets) using MODIS calibrated radiances imagery.

\section{Validation of the MAR simulations}

In the framework of this study, we ran MAR at 15, 20, 25, 30, 40 and $50 \mathrm{~km}$ resolutions to simulate the GrIS SMB over the 1990-2010 period covered by the ERA-INTERIM reanalysis (see the definition of the MAR simulations in Table 1). Given the relative computing time of the $15 \mathrm{~km}$ resolution MAR run compared to the $25 \mathrm{~km}$ resolution, a $10 \mathrm{~km}$ simulation would have required additional computing time, making it unrealistic for this study. Moreover, the hydrostatic hypothesis of the current MAR version cannot be applied to perform such high-resolution runs and the non-hydrostatic version is still under developement. All the simulations were carried out over the same integration domain, except for the $40-50 \mathrm{~km}$ resolution runs (40ed and 50ed) which needed an enlarged domain to keep a reasonable number of grid points between 
the Greenland margins and the domain boundaries. The impact of this extended domain on the MAR results is discussed later in this study (see Sect. 5).

In order to validate our MAR simulations, we have compared the $15-50 \mathrm{~km}$ resolution MAR results with in situ SMB observations along the Kangerlussuaq transect (K-transect), located at $67^{\circ} \mathrm{N}$ in Western Greenland. The stations of the K-transect spread eastwards over the ice sheet, ranging from $4 \mathrm{~km}$ from the western margin up to $140 \mathrm{~km}$ into the GrIS. The surface height of the stations and the annual SMB data of the ice sheet are provided by Van de Wal et al. (2005). For each resolution, we selected the closest pixel to the ice sheet margin at $67^{\circ} \mathrm{N}$, so that all the cross sections start from this pixel and extend on both sides from west to east as the K-transect on the tundra and ice sheet (see Fig. 1). By challenging the outputs with the K-transect data, we were able to assess at each spatial resolution the accuracy of the MAR simulations in the ablation zone and the vicinity of the ice sheet margin. The same cross sections but using the elevation of S9 and S10 to match the relative grid point locations are also presented in the Supplement (Fig. S1).

The comparison between the different topographies and the surface height of the K-transect stations show vertical biases not exceeding $100 \mathrm{~m}$, except along the ice sheet margin where the resolutions used are too coarse to represent the steep slope of the ice sheet between S4 and SHR stations with sufficient accuracy (Fig. 1a). However, it should be noted that the $15-25 \mathrm{~km}$ surface heights form a curve very close to the K-transect data, while the curves formed by $40-50 \mathrm{~km}$ resolution topographies are too smoothed.

These cross sections through the GrIS highlight the relationship between the ice sheet topography and annual snowfall simulated by the MAR model (Fig. 1a and b): higher elevations of the ice sheet surface lead to heavier snowfall. This increase in precipitation is dependent on the slope of the topography and thus on the resolution. Further inland, the precipitation rates stop increasing because the surface slopes are more gentle and temperatures become too cold to add significant snowfall.

Figure 1c illustrates the increasing meltwater run-off when approaching the ice sheet margin, regardless of the spatial resolution. However, we can see that a resolution of 40 $50 \mathrm{~km}$ is too coarse to represent the high run-off rates along the ice sheet margin.

Inland, towards the centre of the GrIS, the SMB is slightly positive but gradually diminishes towards the tundra, finally reaching very low values approaching the ice sheet margin (Fig. 1d). Although the highest resolutions are still insufficient to allow a comparison with the S4, S5 and SHR stations, the shape of the 15,20 and $25 \mathrm{~km}$ resolution cross sections decreasing towards these stations gives encouraging results. The $40-50 \mathrm{~km}$ resolution topographies are modelled as too low-lying between S6 and S9, and consequently the $40-50 \mathrm{~km}$ simulations underestimate the SMB because of the overestimated run-off (see Fig. S2 for a comparison
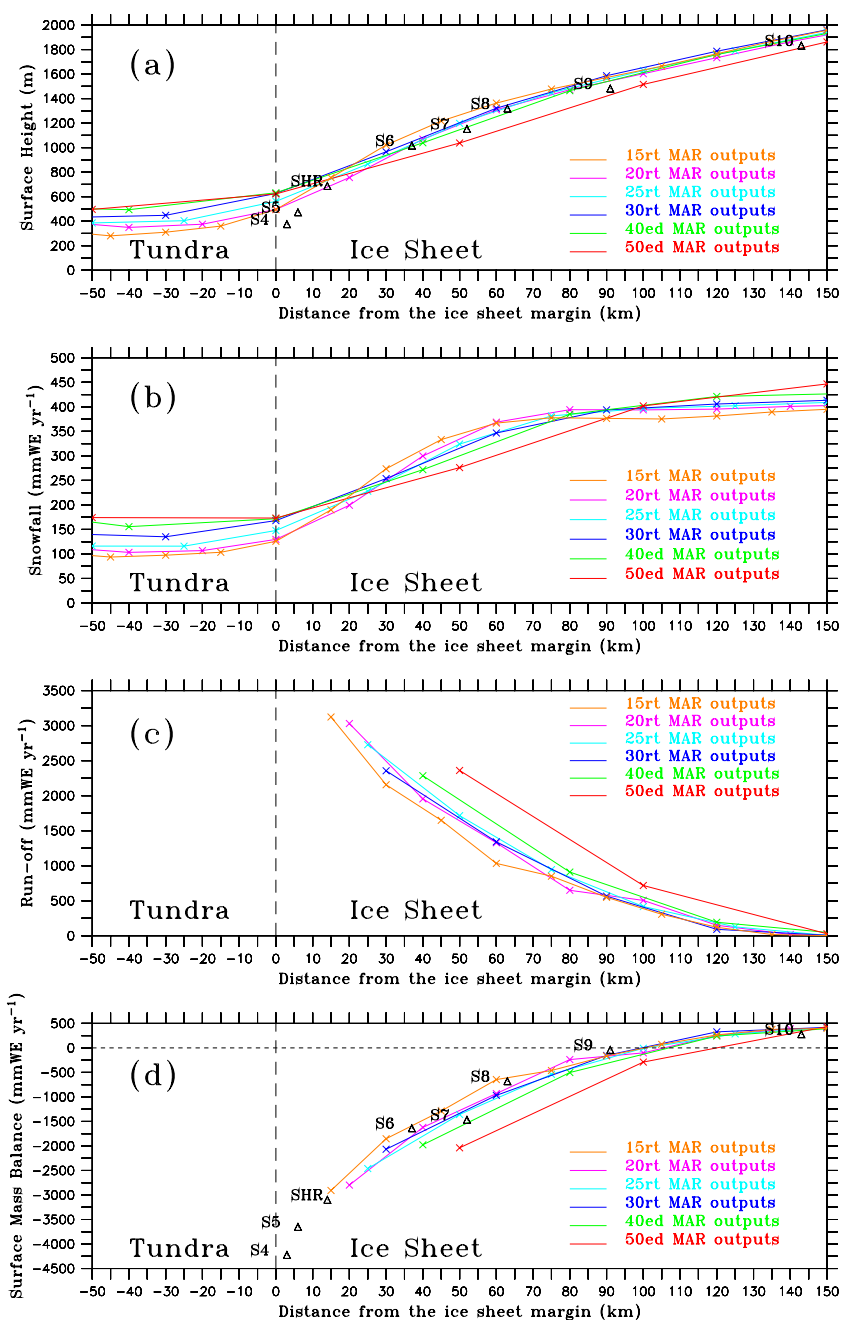

Fig. 1. (a) Cross section of surface height (m) through the GrIS along the K-transect $\left(67^{\circ} \mathrm{N}\right.$, West Greenland) for the $15-50 \mathrm{~km}$ resolution MAR runs, with station data drawn in black symbols.

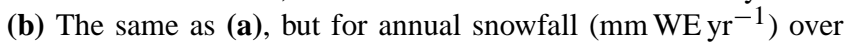
the 1990-2010 period. (c) The same as (b), but for the annual runoff of meltwater $\left(\mathrm{mm} \mathrm{WE} \mathrm{yr}^{-1}\right)$. (d) The same as (b), but for the annual SMB (mm WE $\left.\mathrm{yr}^{-1}\right)$.

between the modelled and observed SMB as function of elevation along the $\mathrm{K}$-transect).

These cross sections show that a minimum resolution of $30 \mathrm{~km}$ is needed to represent the SMB increase as observed between S6 and S9, but resolving S4 and S5 requires resolutions higher than $15 \mathrm{~km}$. Indeed, although most of the $5 \mathrm{~km}$ GrIS topography can be reproduced at a lower resolution according to Fig. 2, a model resolution of at least $10-15 \mathrm{~km}$ is needed to resolve the steep $5 \mathrm{~km}$ slopes in the vicinity of the ice sheet margin, and an even higher-resolution topography (less than $5 \mathrm{~km}$ ) to resemble $\mathrm{S} 4$ and $\mathrm{S} 5$. 
Table 1. Definition of the different MAR simulations performed in the framework of this study, and their related abbrevations.

\begin{tabular}{ll}
\hline Abbreviation & Definition of the MAR simulation \\
\hline $15 \mathrm{rt}$ & $15 \mathrm{~km}$ simulation on Real $15 \mathrm{~km}$ Topography \\
$20 \mathrm{rt}$ & $20 \mathrm{~km}$ simulation on Real $20 \mathrm{~km}$ Topography \\
$25 \mathrm{rt}$ & $25 \mathrm{~km}$ simulation on Real $25 \mathrm{~km}$ Topography \\
$25 \mathrm{st}$ & $25 \mathrm{~km}$ simulation on Smooth $50 \mathrm{~km}$ Topography \\
$30 \mathrm{rt}$ & $30 \mathrm{~km}$ simulation on Real $30 \mathrm{~km}$ Topography \\
$40 \mathrm{ed}$ & $40 \mathrm{~km}$ simulation on real $40 \mathrm{~km}$ topography over Extended Domain \\
$40 \mathrm{od}$ & $40 \mathrm{~km}$ simulation on real $40 \mathrm{~km}$ topography over Original Domain \\
$50 \mathrm{ed}$ & $50 \mathrm{~km}$ simulation on real $50 \mathrm{~km}$ topography over Extended Domain \\
$50 \mathrm{od}$ & $50 \mathrm{~km}$ simulation on real $50 \mathrm{~km}$ topography over Original Domain \\
\hline
\end{tabular}

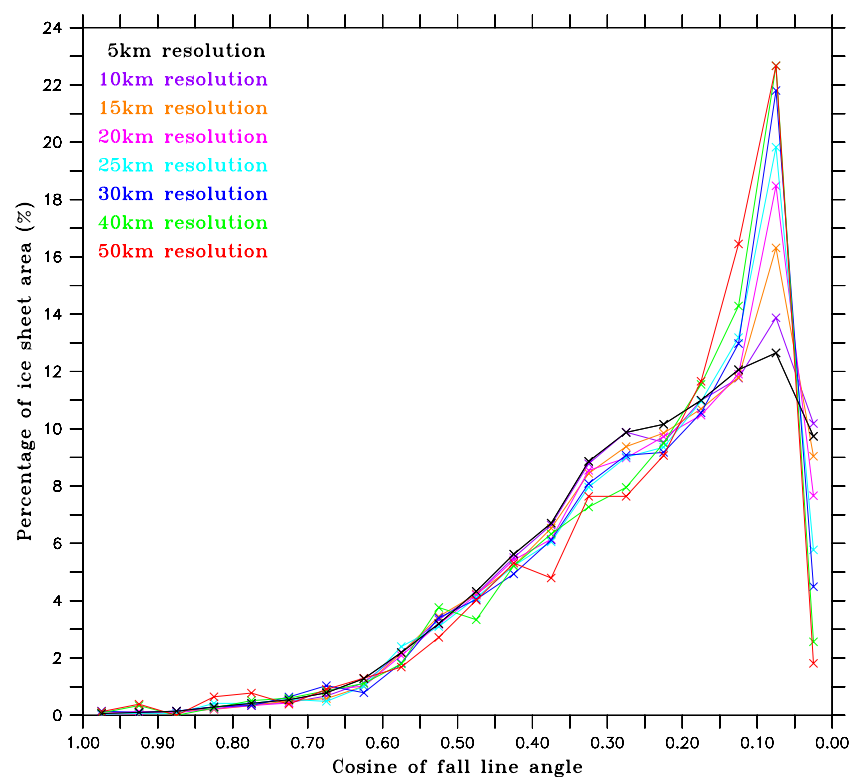

Fig. 2. Distribution (in percentage of the ice sheet area) of the cosine of fall line angle of the $5 \mathrm{~km}$ ice sheet topography of Bamber et al. (2001a,b), interpolated at $10-50 \mathrm{~km}$ resolutions.

\section{Comparison of the MAR resolutions}

As suggested by Table 2, increasing the spatial resolution of MAR requires a large additional computation time (CPU time) to perform the simulation; e.g. running the MAR model at $15 \mathrm{~km}$ resolution takes five times longer than the $25 \mathrm{~km}$ simulation. To reduce the additional computing time needed by the relatively high resolution MAR simulations, we interpolated the outputs produced by the MAR model running at a lower resolution $(20-50 \mathrm{~km})$ onto a higher-resolution grid (here $15 \mathrm{~km}$ ). The intention behind this was to obtain outputs at higher spatial resolution, reliable enough to be used as forcing fields and requiring acceptable computing time to be produced. However, we first had to gauge the lack of information of the interpolated data compared to the results directly provided by the simulations at this higher spatial resolution.

In order to compare simulations at different spatial resolutions, we linearly interpolated (without applying any corrections) the surface height, daily precipitation, meltwater runoff and SMB data onto the $15 \mathrm{~km}$ grid by using the inverse distance weighting of the original pixels situated closest to each new $15 \mathrm{~km}$ pixel (the $15-50 \mathrm{~km}$ resolution ice sheet masks are presented in Fig. S3). Therefore, in order to allow a direct comparison between the MAR simulations, only the ice sheet mask common to all the spatial resolutions has been used here, with the knowledge that the GrIS margins differ slightly between the resolutions.

The averaged annual outputs of the MAR simulations considered here are presented in Table 2. When using the GrIS mask specific to each spatial resolution, the $15-30 \mathrm{~km}$ results are quite close, but the $40-50 \mathrm{~km}$ simulations provide higher SMB values induced by heavier precipitation (for 50ed) or lower run-off (for 40ed). As regards the common ice sheet mask, decreasing the spatial resolution of the MAR model causes the simulated precipitation over the GrIS to increase from $582 \mathrm{Gt} \mathrm{yr}^{-1}$ at $15 \mathrm{~km}$ resolution to $621 \mathrm{Gt} \mathrm{yr}^{-1}$ for $50 \mathrm{ed}$ (these increased precipitation rates will be discussed further later in this study). The increasing run-off when reducing the resolution is not sufficient to counterbalance the heavier precipitation, resulting in higher SMB simulated at lower resolution.

In order to add a statistical approach to our MAR simulations assessment, we also calculated an averaged error on the interpolated outputs (precipitation, run-off and SMB) averaged over the 1990-2010 period compared to the $15 \mathrm{rt}$ results, based on the skill score methodology of Connolley and Bracegirdle (2007). Firstly, we calculated the root mean square (RMS) deviation of the interpolated field (multiannually averaged over the $1990-2010$ period) to the multiannual averaged outputs at $15 \mathrm{~km}$ resolution, normalized by the standard deviation of this $15 \mathrm{~km}$ field to produce $\mathrm{RMS}_{\mathrm{n}}$. Finally, this normalized deviation was rescaled by a function into a weight between 0 and 1 to produce a measure of the model "skill". According to this statistical approach, the 
Table 2. (a) Annual GrIS SMB components simulated by MAR at 15-50 km resolution for the 1990-2010 period on the ice sheet mask specific to each spatial resolution. (b) The same as (a), but on the ice sheet mask common to all the spatial resolutions.

(a) MAR results on the GrIS mask specific to the spatial resolution

\begin{tabular}{ccccccccc}
\hline $\begin{array}{c}\text { MAR } \\
\text { simulation }\end{array}$ & $\begin{array}{c}\text { Estimated } \\
\text { CPU time }\end{array}$ & $\begin{array}{c}\text { GrIS area } \\
\left(10^{3} \mathrm{~km}^{2}\right)\end{array}$ & $\begin{array}{c}\text { Precipitation } \\
\left(\mathrm{Gt} \mathrm{yr}^{-1}\right)\end{array}$ & $\begin{array}{c}\text { PP trend } \\
\left(\mathrm{Gt} \mathrm{yr}^{-1}\right)\end{array}$ & $\begin{array}{c}\text { Run-off } \\
\left(\mathrm{Gt} \mathrm{yr}^{-1}\right)\end{array}$ & $\begin{array}{c}\text { RU trend } \\
\left(\mathrm{Gt} \mathrm{yr}^{-1}\right)\end{array}$ & $\begin{array}{c}\text { SMB } \\
\left(\mathrm{Gt} \mathrm{yr}^{-1}\right)\end{array}$ & $\begin{array}{c}\text { SMB trend } \\
\left(\mathrm{Gt} \mathrm{yr}^{-1}\right)\end{array}$ \\
\hline 15rt & $500 \%$ & 1780 & 642 & -2.22 & 305 & 7.92 & 328 & -10.04 \\
$20 \mathrm{rt}$ & $250 \%$ & 1782 & 648 & -2.38 & 331 & 8.52 & 309 & -10.82 \\
$25 \mathrm{rt}$ & $100 \%$ & 1764 & 649 & -2.44 & 307 & 9.17 & 335 & -11.53 \\
30rt & $66.7 \%$ & 1781 & 657 & -2.60 & 340 & 9.07 & 310 & -11.58 \\
40ed & $25 \%$ & 1742 & 657 & -2.75 & 277 & 9.52 & 375 & -12.20 \\
$50 \mathrm{ed}$ & $12.5 \%$ & 1752 & 666 & -2.76 & 283 & 10.02 & 379 & -12.73 \\
\hline
\end{tabular}

(b) MAR results on the GrIS mask common to all the spatial resolutions

\begin{tabular}{ccccccccc}
\hline $\begin{array}{c}\text { MAR } \\
\text { simulation }\end{array}$ & $\begin{array}{c}\text { Estimated } \\
\text { CPU time }\end{array}$ & $\begin{array}{c}\text { GrIS area } \\
\left(10^{3} \mathrm{~km}^{2}\right)\end{array}$ & $\begin{array}{c}\text { Precipitation } \\
\left(\mathrm{Gt} \mathrm{yr}^{-1}\right)\end{array}$ & $\begin{array}{c}\mathrm{PP} \text { trend } \\
\left(\mathrm{Gt} \mathrm{yr}^{-1}\right)\end{array}$ & $\begin{array}{c}\text { Run-off } \\
\left(\mathrm{Gt} \mathrm{yr}^{-1}\right)\end{array}$ & $\begin{array}{c}\text { RU trend } \\
\left(\mathrm{Gt} \mathrm{yr}^{-1}\right)\end{array}$ & $\begin{array}{c}\text { SMB } \\
\left(\mathrm{Gt} \mathrm{yr}^{-1}\right)\end{array}$ & $\begin{array}{c}\text { SMB trend } \\
\left(\mathrm{Gt} \mathrm{yr}^{-1}\right)\end{array}$ \\
\hline 15rt & $500 \%$ & 1630 & 582 & -2.51 & 165 & 13.36 & 413 & -15.75 \\
$20 \mathrm{rt}$ & $250 \%$ & 1630 & 589 & -2.67 & 176 & 14.22 & 410 & -16.79 \\
$25 \mathrm{rt}$ & $100 \%$ & 1630 & 595 & -2.66 & 181 & 13.98 & 412 & -16.60 \\
30rt & $66.7 \%$ & 1630 & 598 & -2.90 & 189 & 14.42 & 408 & -17.29 \\
40ed & $25 \%$ & 1630 & 610 & -3.00 & 193 & 13.37 & 418 & -16.34 \\
50ed & $12.5 \%$ & 1630 & 621 & -3.03 & 193 & 14.22 & 431 & -17.22 \\
\hline
\end{tabular}
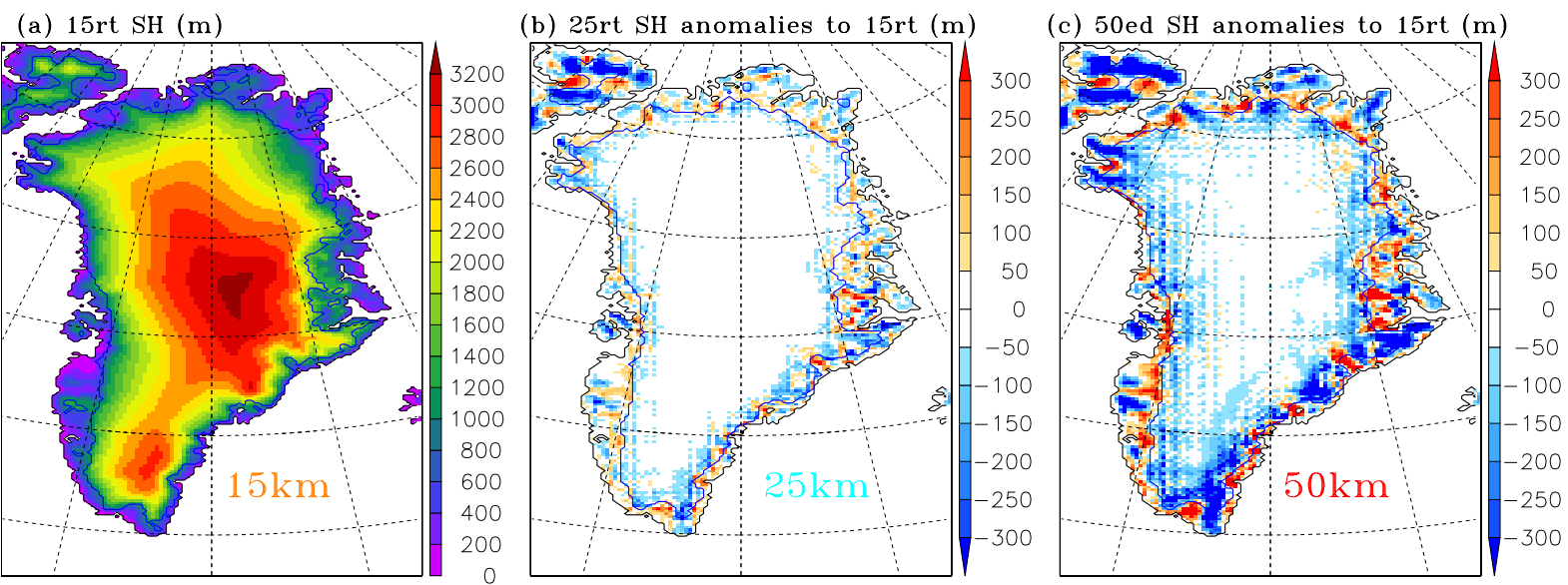

Fig. 3. (a) Surface height (m) of the MAR model at $15 \mathrm{~km}$ resolution (15rt), with the $15 \mathrm{~km}$ ice sheet mask drawn in solid blue line. (bc) Surface height anomalies (m) of the 25 and $50 \mathrm{~km}$ resolution surface height of the MAR model (25rt and 50ed) interpolated onto the $15 \mathrm{~km}$ MAR grid, compared to (a), with the ice sheet mask common to all the spatial resolutions drawn in solid blue line (see the Supplement for the 20,30 and $40 \mathrm{~km}$ surface height anomalies).

interpolated field that receives a skill score close to 1 can be considered highly reliable with respect to the outputs provided by the $15 \mathrm{rt}$ run. We refer to Connolley and Bracegirdle (2007) for further details about the skill score methodology. In Sect. 4, the skill scores are calculated on the common GrIS mask only. The main skill scores calculated in this study are summarized in Table 3.

The same methodology was additionally carried out for each of the annual 15rt outputs (precipitation, run-off, etc.): the RMS deviation of the multi-annual 1990-2010 averaged $15 \mathrm{rt}$ run compared to each annual $15 \mathrm{rt}$ output was normalized by the multi-annual standard deviation over the 19902010 period, and then rescaled between 0 and 1 to obtain multi-annual averaged $15 \mathrm{~km}$ skill scores $(0.31$ for precipitation, 0.79 for run-off, 0.76 for sublimation and evaporation, and 0.54 for SMB). These results allow a comparison with the skill scores calculated on the interpolated outputs: skill 
Table 3. Summary of the main skill scores calculated (a) on the GrIS mask common to all the spatial resolutions, (b) on the $15 \mathrm{~km}$ GrIS mask, and (c) on the $25 \mathrm{~km}$ GrIS mask.

\begin{tabular}{|c|c|c|c|c|c|c|c|c|}
\hline \multicolumn{9}{|c|}{ (a) Comparison on the GrIS mask common to all the spatial resolutions } \\
\hline & \multicolumn{2}{|c|}{ Precipitation } & \multicolumn{2}{|c|}{ Run-off } & \multicolumn{2}{|c|}{ SMB } & \multicolumn{2}{|c|}{ Temperature } \\
\hline & Skill score & Figure & Skill score & Figure & Skill score & Figure & Skill score & Figure \\
\hline 15 rt outputs & / & Fig. 4a & / & Fig. 4d & / & Fig. $4 \mathrm{~g}$ & / & Fig. S9a \\
\hline $20 \mathrm{rt}$ anom. to $15 \mathrm{rt}$ & 0.94 & Fig. S5b & 0.89 & Fig. S7b & 0.90 & Fig. S8b & 0.93 & Fig. S9b \\
\hline $25 \mathrm{rt}$ anom. to $15 \mathrm{rt}$ & 0.86 & Fig. 4b & 0.78 & Fig. $4 \mathrm{e}$ & 0.77 & Fig. $4 \mathrm{~h}$ & 0.86 & Fig. S9c \\
\hline $30 \mathrm{rt}$ anom. to $15 \mathrm{rt}$ & 0.77 & Fig. S5d & 0.74 & Fig. S7d & 0.65 & Fig. S8d & 0.78 & Fig. S9d \\
\hline $40 \mathrm{ed}$ anom. to $15 \mathrm{rt}$ & 0.55 & Fig. S5e & 0.54 & Fig. S7e & 0.38 & Fig. S8e & 0.64 & Fig. S9e \\
\hline $50 \mathrm{ed}$ anom. to $15 \mathrm{rt}$ & 0.36 & Fig. $4 c$ & 0.37 & Fig. 4f & 0.21 & Fig. $4 \mathrm{i}$ & 0.46 & Fig. S9f \\
\hline
\end{tabular}

(b) Comparison on the $15 \mathrm{~km}$ GrIS mask

\begin{tabular}{|c|c|c|c|c|c|c|c|c|}
\hline & \multicolumn{2}{|c|}{ Precipitation } & \multicolumn{2}{|c|}{ Run-off } & \multicolumn{2}{|c|}{ Sublimation } & \multicolumn{2}{|c|}{ SMB } \\
\hline & Skill score & Figure & Skill score & Figure & Skill score & Figure & Skill score & Figure \\
\hline $15 \mathrm{rt}$ outputs & I & Fig. 7d & l & Fig. 7a & I & Fig. S12a & I & Fig. $7 \mathrm{~g}$ \\
\hline $25 \mathrm{rt}$ anom. to $15 \mathrm{rt}$ & 0.85 & Fig. 7e & 0.76 & Fig. $7 b$ & 0.70 & Fig. S12b & 0.75 & Fig. $7 \mathrm{~h}$ \\
\hline Corr. $25 \mathrm{rt}$ anom. to $15 \mathrm{rt}$ & 0.84 & Fig. 7f & 0.85 & Fig. 7c & 0.72 & Fig. S12c & 0.80 & Fig. 7 i \\
\hline
\end{tabular}

(c) Comparison on the $25 \mathrm{~km}$ GrIS mask

\begin{tabular}{|c|c|c|c|c|c|c|c|c|}
\hline & \multicolumn{2}{|c|}{ Precipitation } & \multicolumn{2}{|c|}{ Run-off } & \multicolumn{2}{|c|}{ Sublimation } & \multicolumn{2}{|c|}{ SMB } \\
\hline & Skill score & Figure & Skill score & Figure & Skill score & Figure & Skill score & Figure \\
\hline 25 rt outputs & I & not shown & l & Fig. 8d & I & not shown & l & Fig. $8 \mathrm{~g}$ \\
\hline $25 \mathrm{st}$ anom. to $25 \mathrm{rt}$ & 0.89 & Fig. $8 \mathrm{c}$ & 0.79 & Fig. $8 \mathrm{e}$ & 0.60 & not shown & 0.83 & Fig. $8 \mathrm{~h}$ \\
\hline Corr. $25 \mathrm{st}$ anom. to $25 \mathrm{rt}$ & I & not shown & 0.93 & Fig. $8 \mathrm{f}$ & 0.85 & not shown & 0.90 & Fig. $8 \mathrm{i}$ \\
\hline
\end{tabular}

scores higher than these values are lower than the standard deviation of the $15 \mathrm{rt}$ run over 1990-2010.

\subsection{Surface height anomalies}

According to Fig. 3, the $25 \mathrm{~km}$ topography reveals discrepancies not exceeding $200 \mathrm{~m}$ over the tundra compared to the $15 \mathrm{~km}$ topography, while the biases are less than $100 \mathrm{~m}$ along the GrIS margin and close to 0 in the centre of the ice sheet. These anomalies considerably increase for the lower resolutions (40-50 km), especially along the south-eastern coast of Greenland, which is characterized by a huge orography, with biases higher than $300 \mathrm{~m}$ (see Fig. S4 for the 20, 30 and $40 \mathrm{~km}$ surface height anomalies). On average, over the centre part of the ice sheet, the $20-50 \mathrm{~km}$ topographies generally underestimate the $15 \mathrm{~km}$ surface height, and are more levelled at close proximity to the ice sheet margins. To a large degree, the differences between SMB components at different resolutions clearly come from this smooth orography.

\subsection{Annual precipitation anomalies}

The $20-25 \mathrm{~km}$ resolution outputs interpolated onto the $15 \mathrm{~km}$ MAR grid match the $15 \mathrm{rt}$ precipitation outputs with a high degree of accuracy (Fig. 4b) (the 20, 30 and $40 \mathrm{~km}$ anomalies are presented in Fig. S5), with anomalies generally less than 0.5 standard deviations (except locally over the tundra) and high skill scores (0.94 and 0.86) compared to the $15 \mathrm{~km}$ standard deviation skill score (0.31). These precipitation anomalies slightly increase (up to 1 standard deviation) for the 30rt outputs due to (1) an overestimation of the precipitation within the ice sheet and (2) an underestimation around the margin where the interpolated topography is overly level compared to the $15 \mathrm{~km}$ topography. However, these discrepancies remain quite moderate with a skill score of 0.77 . Finally, the 40 and $50 \mathrm{~km}$ resolution precipitation fields, too high on the GrIS and ocean and too low around the margin, show anomalies reaching up to 2 standard deviations (Fig. 4c). At low spatial resolution, the underestimated surface height in the coastal regions compared to the hilly $15 \mathrm{~km}$ topography dampens the topographic barrier effect and results in more moisture being brought towards the interior of the ice sheet.

The $15-50 \mathrm{~km}$ precipitation outputs were also compared to Jason Box's GrIS accumulation map (http://bprc.osu. edu/wiki/Greenland_Accumulation_Grids) over 1990-2008 (Fig. S6). This comparison over the common GrIS mask revealed skill scores diminishing with decreasing MAR resolution (from 0.28 at $15 \mathrm{~km}$ to 0.10 at $50 \mathrm{~km}$ ). 

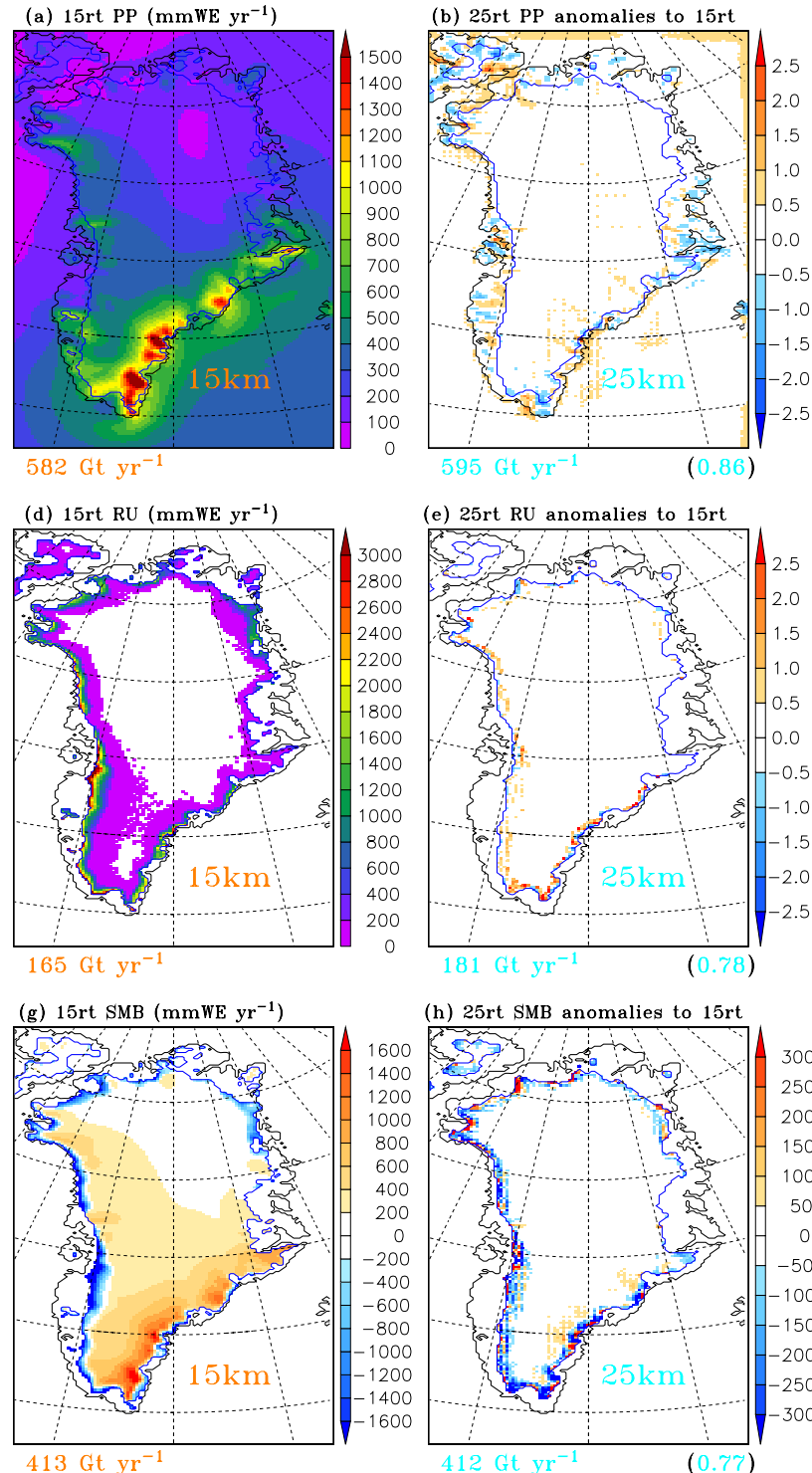
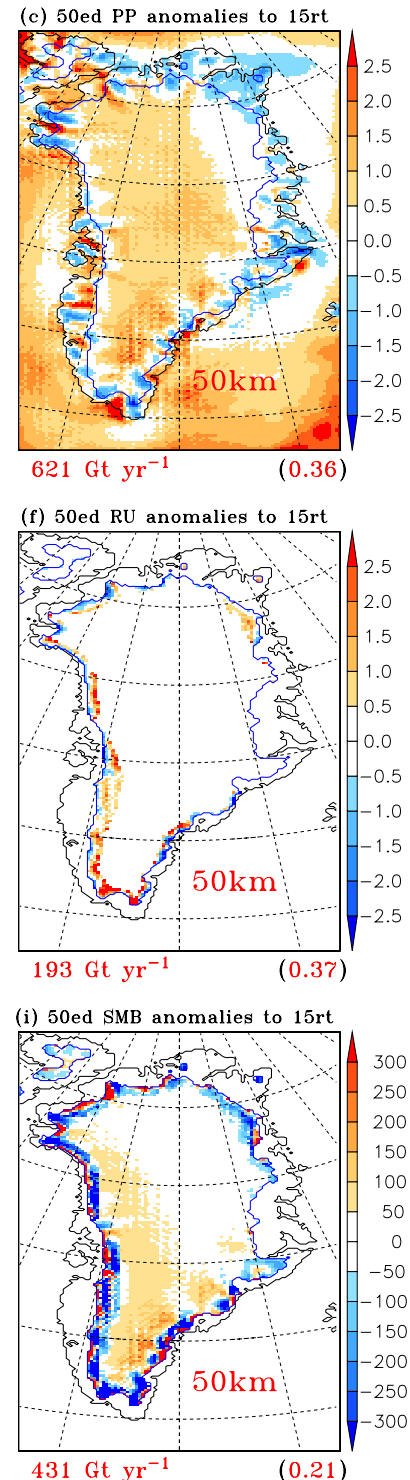

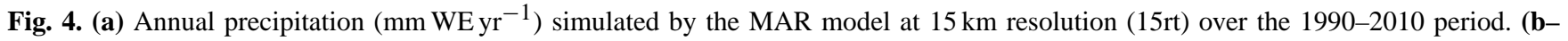
c) Annual precipitation anomalies (in standard deviation) of the 25 and $50 \mathrm{~km}$ resolution MAR outputs (25rt and 50ed) interpolated onto the $15 \mathrm{~km}$ MAR grid, compared to (a). On the bottom left side of each view is the annual amount of precipitation $\left(\mathrm{Gt}^{\mathrm{yr}}{ }^{-1}\right)$ on the ice sheet mask common to all the spatial resolutions, drawn in solid blue line. On the bottom right side of each view, in brackets, is the skill score of the $25 \mathrm{rt}$ and 50ed field compared to the $15 \mathrm{rt}$ outputs, on the common GrIS mask. (d-f) The same as (a-c), but for the annual run-off (mm WE $\mathrm{yr}^{-1}$ ). (g-i) The same as (d-f), but for the annual SMB (mm WE yr $\left.{ }^{-1}\right)$. See the Supplement for the 20, 30 and $40 \mathrm{~km}$ resolution anomalies.

\subsection{Anomalies of meltwater run-off}

The 20-25 km run-offs compared quite well with the $15 \mathrm{~km}$ simulation (Fig. 4e) and both have high skill scores $(0.89$ and 0.78 ) with respect to the $15 \mathrm{~km}$ standard deviation skill score (0.79). Most of the anomalies lie along the southern and western GrIS margins where the run-off is underestimated in the closest vicinity of the margin (less than 1 standard deviation), and overestimated (up to 2 standard deviations) towards the interior of the central ice sheet. Compared to the annual run-off rate in these bordering regions, especially in the western and southern parts where it exceeds $3000 \mathrm{~mm} \mathrm{WE} \mathrm{yr}^{-1}$, the biases represent less than $10 \%$ of the annual run-off. The discrepancies are more constrained to the border of the ice sheet in Northern and Eastern Greenland, where the melting rate is lower

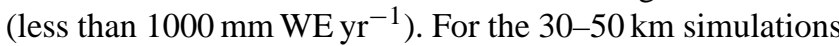
(Fig. 4f), the biases are largely strengthened (often exceeding $300 \mathrm{~mm} \mathrm{WE} \mathrm{yr}^{-1}$ and 2 standard deviations) in the southern and western GrIS and gradually spread out further towards 
the interior of the ice sheet, resulting in diminishing skill scores $(0.74,0.54$ and 0.37$)$.

Comparison with the $15 \mathrm{rt}$ run revealed underestimation along the margin and overestimation towards the interior of the ice sheet, related to the different topographies between the investigated resolutions, as previously highlighted by the cross sections along the K-transect (see Fig. 1). Steeper ice sheet slopes towards the tundra simultaneously induce lower surface height along the GrIS border and higher surface height towards the interior of the ice sheet, meaning that higher-resolution runs simulate increased melting rates along the ice sheet border and decreased rates inland. According to the comparison between the $20-50 \mathrm{~km}$ near-surface temperature and the 15rt MAR outputs (see Fig. S9), the anomalies pattern is in full agreement with the topography and run-off discrepancies (Fig. S7) that have been highlighted here.

\subsection{Anomalies in surface mass balance}

The pattern of the $20-30 \mathrm{~km}$ SMB anomalies (see Figs. $4 \mathrm{~h}$ and S8) with respect to the 15rt outputs is related to the run-off discrepancies observed previously (see Fig. 4d-f). Indeed, the underestimated run-off along the ice sheet margin produces positive anomalies of annual SMB (up to $300 \mathrm{~mm} \mathrm{WE} \mathrm{yr}^{-1}$ for the $40-50 \mathrm{~km}$ runs) compared to the $15 \mathrm{rt}$ outputs, and overestimated melting generates negative anomalies towards the interior of the ice sheet (generally exceeding $300 \mathrm{~mm} \mathrm{WE} \mathrm{yr}^{-1}$ for the lower resolutions). Moreover, the heavier precipitation over the ice sheet simulated by the MAR model at $40-50 \mathrm{~km}$ resolutions is responsible for the strengthened SMB observed within the central parts of the GrIS (see Fig. 4i).

\subsection{Inter-annual variability}

The next important issue to investigate was the inter-annual variability of the MAR results coming from simulations at different spatial resolutions. Indeed, if the resolution impacts the inter-annual variability, this could harshly challenge the reliability of the MAR simulations to study anomalies related to the spatial resolution.

According to Fig. 5, the MAR simulations at all resolutions present the same inter-annual variability of the SMB components. Moreover, the record melt years (e.g. 2003, 2008 and 2010) as well as the annual precipitation peaks (e.g. 1996 and 2008) are generally well reproduced by the MAR model whatever its spatial resolution. Figure 5a illustrates the very slight decrease (approximately of $50 \mathrm{Gt} \mathrm{yr}^{-1}$ ) of the annual precipitation simulated by the MAR model at all resolutions from 1990 to 2010. Conversely, from 1990 to 2010 the MAR model produced an increase of the run-off between 150 and $200 \mathrm{Gt} \mathrm{yr}^{-1}$ (Fig. 5b), inducing a negative trend of SMB over the reference period (up to $-10 \mathrm{Gt} \mathrm{yr}^{-2}$ ), as plotted in Fig. 5c. This comparison proves that the MAR
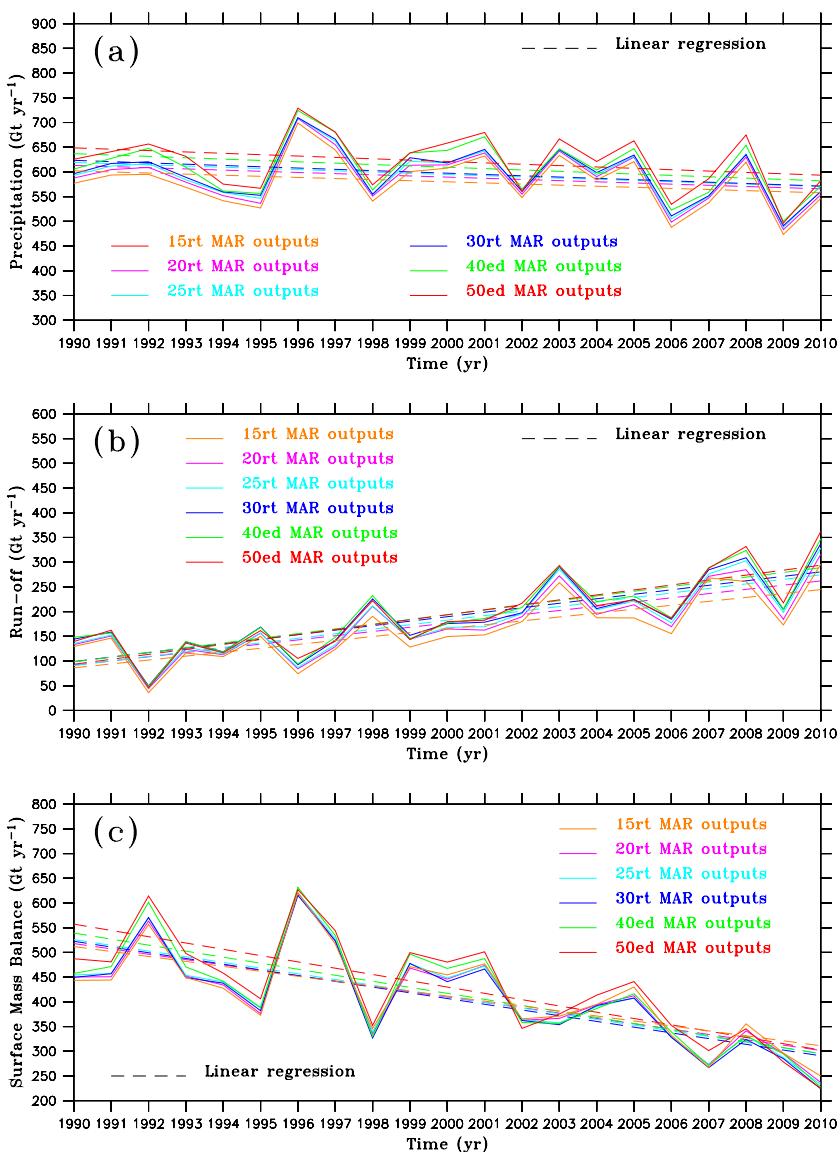

Fig. 5. (a) Annual precipitation $\left(\mathrm{Gt} \mathrm{yr}^{-1}\right)$ on the GrIS simulated by the MAR model at $15-50 \mathrm{~km}$ resolution (in solid lines), over the ice sheet mask common to all the spatial resolutions. The $20-50 \mathrm{~km}$ resolution outputs have been interpolated onto the $15 \mathrm{~km}$ MAR grid. The linear regressions throughout the 1990-2010 period are drawn in dashed lines. (b) The same as (a), but for the annual run-off of meltwater $\left(\mathrm{Gt} \mathrm{yr}^{-1}\right)$ from the GrIS. (c) The same as (a), but for the annual GrIS SMB $\left(\mathrm{Gt} \mathrm{yr}^{-1}\right)$.

model produces consistent results throughout this period for runs at high or low spatial resolution.

Nevertheless, when examined in more detail, some differences between spatial resolutions in the run-off values for 2005 or 2008 were revealed (Fig. 5b): the higher the resolution, the lower the run-off. Such discrepancies are an artefact due to the use of an ice sheet mask common to all the resolutions. Indeed, according to Table 2, the $40-50 \mathrm{~km}$ GrIS margins (where most of the run-off increase takes place) are included in the common ice sheet mask, while a larger number of $15 \mathrm{~km}$ pixels located in the vicinity of the $15 \mathrm{~km}$ resolution margin are not contained in the common mask. This explains why the higher-resolution melting values appear to be slightly dampened throughout the 1990-2010 period compared to the low-resolution MAR runs (Fig. 5b). Conversely, if the ice sheet masks specific to each simulation were used, the differences in the run-off trend disappeared (see Table 2 
and Fig. S10). As regards precipitation, the trends are still slightly more important for the low-resolution MAR runs, whatever the common (Fig. 5) or specific (Fig. S10) ice sheet masks.

As seen in Fig. 5a and previously observed in Fig. 4a-c, the MAR model produced heavier precipitation on average over the ice sheet with decreasing spatial resolution, even if the inter-annual variability does not seem to be influenced by the spatial interpolation. Such increased precipitation simulated by a RCM when decreasing its spatial resolution has already been observed on the GrIS with HadRM3 (J. L. Bamber and C. Vernon, personal communication, 2011). Conversely, RACMO produces heavier precipitation in Greenland for higher-resolution runs (Ettema et al., 2009) due to enhanced orographic precipitation in South-Eastern Greenland. For even higher spatial resolutions, this increase in RACMO stops since more high accumulation points fall outside the GrIS mask. The following sections present several MAR experiments, which attempt to explain the increased precipitation simulated by the low-resolution MAR runs.

\section{Impact of the domain size}

As previously mentioned, the integration domain of the 40$50 \mathrm{~km}$ resolution MAR runs was enlarged $\left(11.2 \times 10^{6} \mathrm{~km}^{2}\right)$ in comparison with the other simulations $\left(7.0 \times 10^{6} \mathrm{~km}^{2}\right)$, in order to ensure a sufficient number of pixels between the Greenland limits and domain boundaries. Indeed, if the model boundaries are too close to Greenland, the precipitation over the ice sheet is overestimated because MAR needs several pixels from the domain boundaries before simulating precipitation, and hence no precipitation is seen to occur over the ocean. For this reason, it was necessary to investigate whether these different domain sizes could impact on the precipitation simulated by the MAR model at $40-50 \mathrm{~km}$ resolutions. Indeed, a wider domain involves a larger ocean area, which could eventually increase the water evaporation in MAR, in turn bringing more moisture to the ice sheet. For this reason, the $40-50 \mathrm{~km}$ resolution MAR model was run over the original domain (as for the other MAR resolutions) with the same set-up.

As mentioned before, the $40-50 \mathrm{~km}$ simulations over the smaller domain (40od and 50od) generated somewhat heavier precipitation on the GrIS $\left(\sim 20 \mathrm{Gt} \mathrm{yr}^{-1}\right.$ at $40 \mathrm{~km}$ resolution and $\sim 50 \mathrm{Gt} \mathrm{yr}^{-1}$ at $50 \mathrm{~km}$ resolution) than over the extended domain (40ed and 50ed) (Fig. 6). Nevertheless, these GrIS precipitation anomalies between both domains are generally not significant (less than 1 standard deviation and $16 \%$ ) and remain restricted to the north-eastern part of the ice sheet. This is explained by the proximity of the northeastern boundary of the domain, resulting in additional moisture observed at the eastern ice sheet.

According to this comparison, the enlarging of the integration domain cannot be responsible for the MAR model

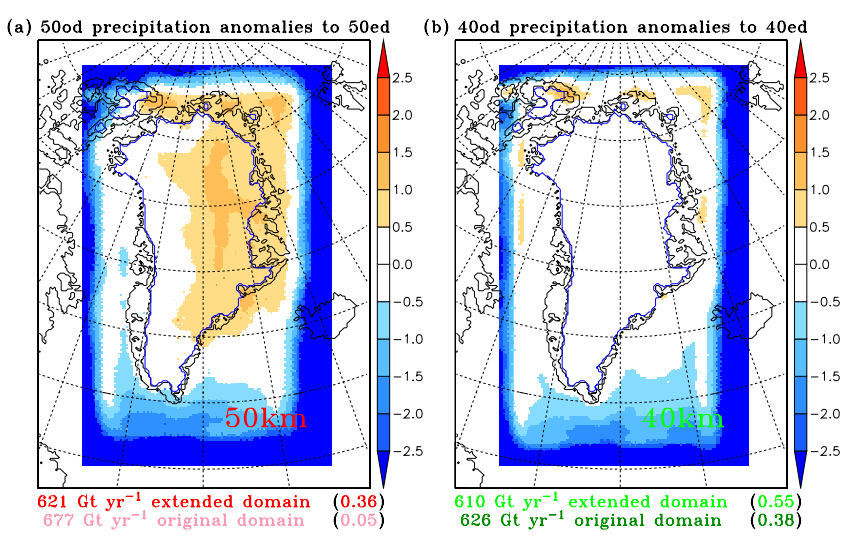

Fig. 6. (a) Annual precipitation anomalies (in standard deviation) of the $50 \mathrm{~km}$ resolution outputs from the MAR model running over the original domain $(50 \mathrm{od})$, compared to the $50 \mathrm{~km}$ resolution outputs from MAR simulation over the extended domain (50ed), over the 1990-2010 period. Positive (negative) anomalies mean higher (lower) precipitation simulated by 50od than 50ed. On the bottom left side of the view is the annual amount of precipitation $\left(\mathrm{Gt} \mathrm{yr}^{-1}\right)$ from 50ed (in red) and 50od (in pink). On the bottom right side of the view, in brackets, is the skill score of 50ed (in red) and 50od (in pink) compared to the $15 \mathrm{~km}$ MAR outputs (15rt). (b) The same as (a), but for the 40ed (in clear green) and 40od (in dark green).

producing heavier precipitation on the GrIS with decreasing spatial resolution: a larger domain is required here for a better comparison with the higher-resolution results (see skill scores in Fig. 6). Moreover, the domain size does not impact the run-off simulation (not shown here).

\section{Enhanced GrIS SMB interpolation}

Section 4 highlighted some biases within the fields of precipitation, run-off and SMB coming from the different spatial resolutions investigated in this study. However, while these biases gradually increase with reduced spatial resolution, the $20-25 \mathrm{~km}$ resolution runs provided quite reliable results compared to the $15 \mathrm{rt}$ outputs. Moreover, as the $20-25 \mathrm{~km}$ simulations require a reasonable computing time, their outputs interpolated at a higher spatial resolution can be considered a suitable alternative to the very high-resolution results required to act as forcing fields of an ice dynamical model. We therefore sought to dampen the anomalies of the SMB components we have highlighted between the $20-50 \mathrm{~km}$ results and the 15rt MAR outputs in order to produce more reliable SMB fields as potential forcing fields for higherresolution simulations. Nonetheless, although most of the SMB components can be captured by the $15-25 \mathrm{~km}$ resolution runs, the rugged parts of the GrIS in the closest vicinity of the margin require an even higher resolution to be resolved (Fig. 1). 


\subsection{Method}

This section details the correction of the $25 \mathrm{~km}$ outputs (25rt) interpolated onto the $15 \mathrm{~km}$ ice sheet mask to reduce the anomalies with respect to the $15 \mathrm{~km}$ MAR SMB components (15rt) by applying a correctional factor to each interpolated point (taking into account the differences between the $15 \mathrm{~km}$ and the $15 \mathrm{~km}$ interpolated $25 \mathrm{~km}$ topographies): an explanatory figure is presented in the Supplement (Fig. S11). For each point of the $15 \mathrm{~km}$ grid, we identified the eight ice sheet points from the $25 \mathrm{~km}$ grid the closest to this $15 \mathrm{~km}$ grid point. For each pair of these eight points, a local vertical gradient of the SMB component was calculated (at a daily time scale) according to the difference in surface height on the $25 \mathrm{~km}$ resolution grid. Then these vertical gradients were averaged by the total difference in elevation between the eight $25 \mathrm{~km}$ points to produce a daily vertical gradient of the SMB component, specific to the $15 \mathrm{~km}$ grid point. Finally, as correction factors, this daily vertical gradient was applied to correct the $25 \mathrm{rt} \mathrm{SMB}$ component interpolated onto the $15 \mathrm{~km}$ grid according to the difference between the interpolated $25 \mathrm{~km}$ surface height and the original $15 \mathrm{~km}$ topography on this point. The use of vertical weighting (instead of a simple average) in the gradient computation aimed to dampen the influence of "extreme" local gradients; i.e. a strong variation of the SMB component between two $25 \mathrm{~km}$ points located almost at the same surface height generates a very large gradient. Finally, if the $15 \mathrm{~km}$ point lies beneath all the eight closest $25 \mathrm{~km}$ points (e.g. along the ice sheet margin), only the maximum local gradient was taken into account in order to strengthen the correction.

This correction was applied to each SMB component separately (snowfall (SF), rainfall (RF), run-off of meltwater (RU), sublimation and evaporation (SU)). The SMB was afterwards reconstructed (with $\mathrm{SMB}=\mathrm{SF}+\mathrm{RF}-\mathrm{RU}-\mathrm{SU}$ ). As the forcing fields for ice dynamical models are required over all ice sheet pixels of these models, the $25 \mathrm{rt}$ outputs were interpolated onto the whole $15 \mathrm{~km}$ ice sheet mask (instead of using a mask common to all the spatial resolutions) to allow a more reliable comparison with the $15 \mathrm{rt}$ outputs. Another implementation of local gradients for accumulation and ablation regimes, based on the method of Helsen et al. (2012), was tested here but did not produce results as good as those achieved using our method when applied to the SMB components.

\subsection{Run-off of meltwater}

Figure $7 \mathrm{a}-\mathrm{c}$ illustrate the significant improvement (a skill score of 0.85 instead of 0.76 previously) brought about by the application of the correction factors to the $25 \mathrm{rt}$ run-off when compared to the 15rt MAR outputs in the 1990-2010 period. Indeed, while the annual run-off anomalies could locally reach up to 2 standard deviations in Southern Greenland without correction (Fig. 7b), these biases were significantly reduced to, on average, less than 1 standard deviation after applying the daily gradients (Fig. 7c). Moreover, the positive run-off anomalies previously observed around the western border regions of the GrIS were dampened almost to the point of deletion.

Nevertheless, some improvements were still required in the closest vicinity of the GrIS margin, where even the maximum local gradients were unable to satisfactorily strengthen the higher run-off values, causing negative anomalies exceeding 1 standard deviation at these points. The surface height of the ice sheet at $15 \mathrm{~km}$ resolution becomes very steep when approaching the margin, which increases the run-off. Unfortunately, the $25 \mathrm{~km}$ topography cannot match this gradient so close to the GrIS border. Furthermore, we do not have any $25 \mathrm{~km}$ resolution ice sheet point located just beyond the margin, beneath the elevation of the $15 \mathrm{~km}$ point located closest of the GrIS margin, to represent with full reliability the increasing gradient of the surface height. Therefore, despite the use of the maximum local gradients, the runoff gradients of the $15 \mathrm{~km}$ interpolated $25 \mathrm{rt}$ points located in close proximity to the GrIS margin could be slightly underestimated, making the correction factor insufficient to significantly reduce the negative anomalies along the border of the ice sheet. In addition, at the beginning of the melt season, bare ice appears earlier over the original $15 \mathrm{~km}$ pixel (inducing high run-off rates), while the closest $25 \mathrm{~km}$ pixels, higher in altitude, are still covered by melting snow, retaining a large part of the meltwater. Consequently, the local gradients derived from these $25 \mathrm{~km}$ pixels are not fully reliable when used in place of a $15 \mathrm{~km}$ interpolated $25 \mathrm{rt}$ pixel.

Due to both the significant reduction of positive anomalies within the ice sheet and better reproduction of the high melting rate in the marginal region, the interpolated $25 \mathrm{rt}$ total runoff from the GrIS ice sheet was increased from $291 \mathrm{Gt} \mathrm{yr}^{-1}$ to $300 \mathrm{Gt} \mathrm{yr}^{-1}$ after applying the correction factors.

\subsection{Sublimation and evaporation}

As previously for run-off, the same methodology was applied to the 25rt daily sublimation and evaporation from the MAR model. Before correction, the $25 \mathrm{rt}$ outputs strongly overestimated the sublimation and evaporation along the GrIS margin (up to 2.5 standard deviations) and caused overestimated deposition within the central ice sheet (up to -1.5 standard deviation) compared to the 15rt outputs (see Fig. S12). Applying the correction factors to the $25 \mathrm{rt}$ outputs resulted in dampening the positive anomalies of sublimation and evaporation around the ice sheet margin, thereby enhancing the skill score to 0.72 (instead of the original 0.70 ).

\subsection{Snowfall and rainfall}

After applying the correction factors to the daily precipitation (snowfall and rainfall) from the $25 \mathrm{rt}$ run, no further improvement could be made comparative to the 15rt MAR 
(a) $15 \mathrm{rt} \mathrm{RU}\left(\mathrm{mmWE} \mathrm{yr}^{-1}\right)$

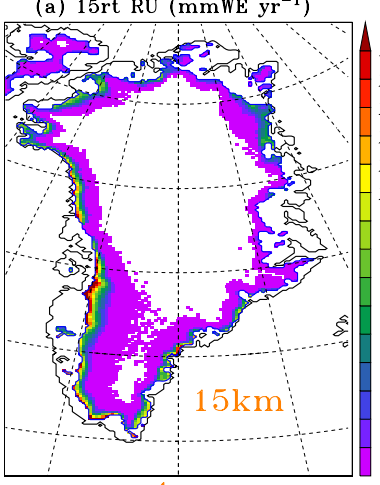

305 Gt yr

(d) $15 \mathrm{rt} \mathrm{PP}\left(\mathrm{mmWE} \mathrm{yr}^{-1}\right)$

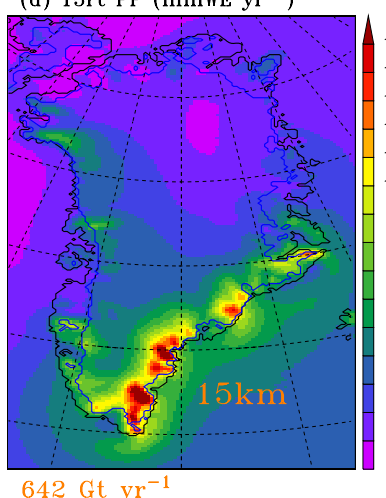

(g) $15 \mathrm{rt} \mathrm{SMB}\left(\mathrm{mmWE} \mathrm{yr}^{-1}\right)$

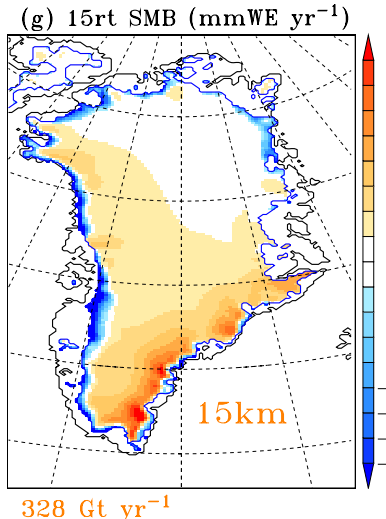

(b) $25 \mathrm{rt} \mathrm{RU}$ anomalies to $15 \mathrm{rt}$

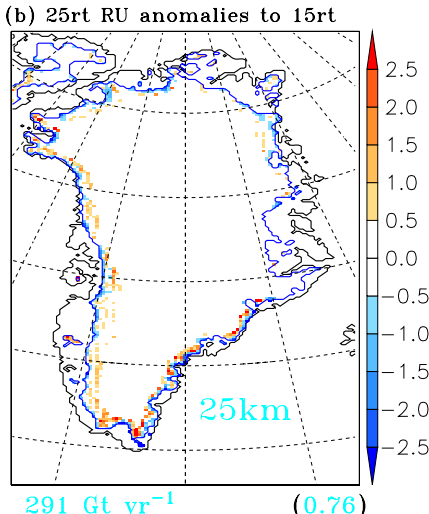

(e) $25 \mathrm{rt} \mathrm{PP}$ anomalies to $15 \mathrm{rt}$

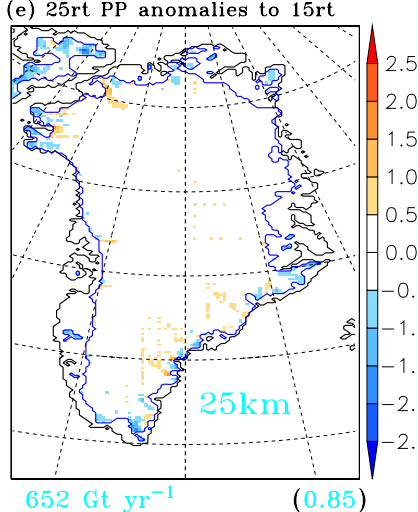

(h) $25 \mathrm{rt}$ SMB anomalies to $15 \mathrm{rt}$

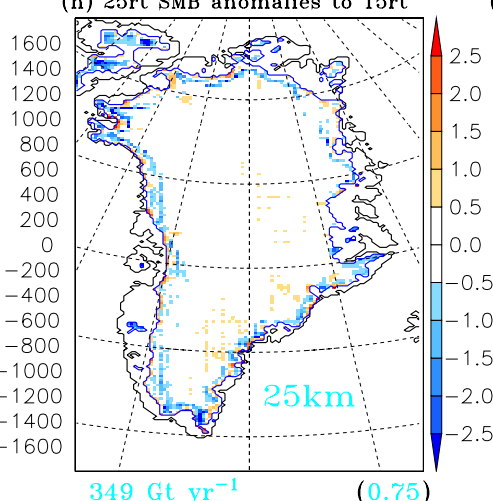

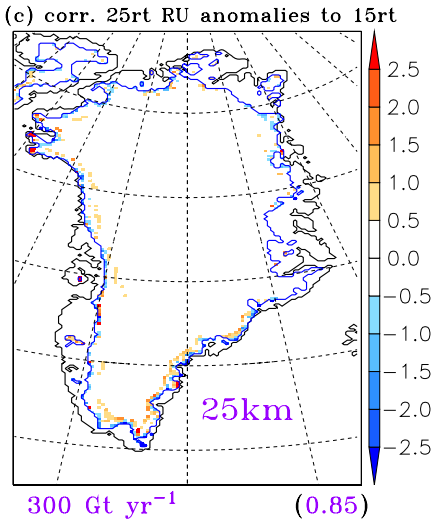

(f) corr. 25rt PP anomalies to $15 \mathrm{rt}$

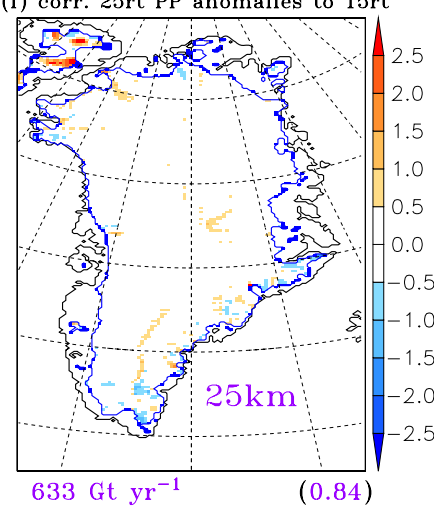

(i) reconstr. 25rt SMB anomalies to $15 \mathrm{rt}$

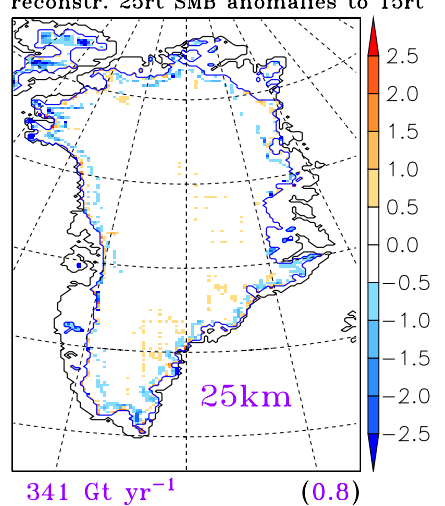

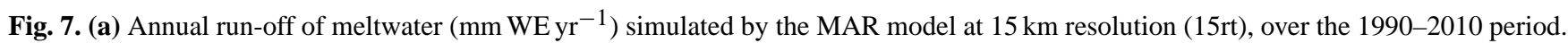
On the bottom left side of the view is the total run-off of meltwater $\left(\mathrm{Gt} \mathrm{yr}^{-1}\right.$ ) from the GrIS, on the $15 \mathrm{~km}$ ice sheet mask. (b) Annual run-off anomalies (in standard deviation) of the $25 \mathrm{~km}$ resolution outputs (25rt) interpolated onto the $15 \mathrm{~km}$ ice sheet mask, compared to (a). On the bottom right side, in brackets, is the skill score of the interpolated field compared to the $15 \mathrm{rt}$ outputs. (c) The same as (b), but for the $25 \mathrm{rt}$ outputs interpolated onto the $15 \mathrm{~km}$ GrIS mask and corrected with daily gradients. (d-f) The same as (a-c), but for the annual precipitation $\left(\mathrm{mm} \mathrm{WE} \mathrm{yr}^{-1}\right)$ simulated by the MAR model. $(\mathbf{g}-\mathbf{i})$ The same as $(\mathbf{a}-\mathbf{c})$, but for the annual SMB $\left(\mathrm{mm} \mathrm{WE} \mathrm{yr}^{-1}\right)$ simulated by the MAR model, and the reconstructed SMB from the corrected 25rt outputs.

outputs (Fig. 7d-f). The main precipitation pattern and its inter-annual variability are determined by atmospheric circulation, specifically by cyclonic activity and the main storm tracks around Greenland (Dethloff et al., 2002). Moreover, the precipitation rate is not a linear function of the surface height of Greenland (Fig. S13). Therefore, daily gradients of precipitation according to the local difference of elevation are quite unreliable for implementing suitable correction factors to this field.

Nevertheless, as the annual precipitation anomalies between the $25 \mathrm{rt}$ results and the $15 \mathrm{rt}$ outputs were quite limited (less than $10 \%$, as previously observed in Sect. 4), and the 
related comparison benefits from a high skill score (0.85), the snowfall and rainfall outputs simulated by the 25rt MAR run without correction can be used to approximately reconstruct the GrIS SMB field at $15 \mathrm{~km}$ resolution.

\subsection{Reconstructed GrIS SMB}

From the snowfall and rainfall simulated by the MAR model at $25 \mathrm{~km}$ resolution and interpolated onto the $15 \mathrm{~km}$ ice sheet mask, as well as the run-off, sublimation and evaporation previously corrected by daily gradients, we can reconstruct the GrIS SMB field over the 1990-2010 period at a $15 \mathrm{~km}$ resolution (Fig. 7g-i).

As highlighted by the annual anomalies in Fig. $7 \mathrm{~h}$ and i, the reconstructed SMB field represents an improvement compared to the 25rt SMB interpolated onto the $15 \mathrm{~km}$ MAR grid (with a skill score of 0.75 increased to 0.80 ). Nevertheless, this improvement is limited by the inability of the correction factors to adequately strengthen the melting rate in the closest vicinity of the GrIS margin, causing continued positive anomalies of SMB locally along the border of the ice sheet while slightly reducing the SMB of the whole GrIS (from $349 \mathrm{Gt} \mathrm{yr}^{-1}$ to $341 \mathrm{Gt} \mathrm{yr}^{-1}$ ). In South-Eastern Greenland, the discrepancies observed around the coastal region are related to the differences in annual precipitation between the MAR simulations at 25 and $15 \mathrm{~km}$ resolutions which are not corrected when reconstructing the $15 \mathrm{~km} \mathrm{SMB}$.

Furthermore, we carried out the same reconstruction of the $15 \mathrm{~km}$ GrIS SMB field over the 1990-2010 period from the 25rt MAR outputs, but using daily gradients determined on each grid point according to the four and twelve closest points at $25 \mathrm{~km}$ resolution (instead of the eight closest points as outlined previously), with the aim to test the strength of the daily gradient implementation. As highlighted in Table 4a, the variation of the field around each grid point is not significantly influenced by the number of reference points we take into account in the daily gradient calculation. On the other hand, further expanding the investigated zone around each grid point in the vertical gradient implementation would not be reliable because we would lose the "local skill" of the daily gradients specific to each grid point.

In order to estimate the maximum spatial resolution YY km of the MAR model required to obtain reliable SMB outputs at a higher resolution $\mathrm{XX} \mathrm{km}$, the method implemented in this study was also used to interpolate and correct the RU and SU outputs from different MAR simulations onto higher-resolution GrIS masks. The related skill scores and SMB results are summarized in Table 5. This table shows that a maximal resolution of less than twice the desired spatial resolution ( $\mathrm{YY} \mathrm{km}<2 \times \mathrm{XX} \mathrm{km}$ ) is needed to produce reliable interpolated SMB results at XX km resolution, otherwise too large biases (assessed by the skill scores) remain after interpolation.

\section{Impact of a coarse topography}

The GrIS topography is very steep in the margin regions and the complicated orographic features around the borders can only be fully resolved with a horizontal resolution higher than $25 \mathrm{~km}$ (Stendel et al., 2008). As previously pointed out, the $15-50 \mathrm{~km}$ MAR simulations use different topographies according to the spatial resolution, and this impacts the MAR outputs. Therefore, the effect of a smooth topography is here investigated by analyzing high-resolution simulations using lower-resolution topography. We also applied the enhanced SMB interpolation developed in this study to the MAR results provided by the coarse-topography run to investigate whether this SMB interpolation is able to significantly reduce the anomalies generated by another topography, and hence to test the reliability of our method.

For this purpose, we interpolated the $50 \mathrm{~km}$ resolution MAR topography onto the $25 \mathrm{~km}$ resolution grid and run the MAR model at $25 \mathrm{~km}$ resolution throughout the 1990 2010 period covere by the ERA-INTERIM reanalysis, using the original $25 \mathrm{~km}$ ice sheet mask (25st). As in Sect. 6, the run-off (Fig. 8d-f), sublimation and evaporation were corrected by applying daily gradients to each grid point, implemented from the $25 \mathrm{~km}$ resolution MAR outputs provided by the coarse topography run (25st), and taking into account the discrepancies of surface height between the original $25 \mathrm{~km}$ topography (from 25rt) and the coarse topography. Finally, the $25 \mathrm{~km}$ resolution GrIS SMB field was reconstructed by using these corrected outputs and the precipitation pattern produced by the 25 st MAR run (Fig. $8 \mathrm{~g}-\mathrm{i}$ ).

According to Fig. $8 \mathrm{a}$, the $50 \mathrm{~km}$ surface height appears to be generally too low around the whole eastern border of the GrIS where the topography is actually very hilly (with large biases reaching up to $-300 \mathrm{~m}$ ), but conversely overestimated along the western margin compared to the original $25 \mathrm{~km}$ topography. Due to these surface height anomalies, the $25 \mathrm{st}$ MAR run simulated higher annual near-surface temperatures in Eastern Greenland (locally exceeding 1.5 standard deviation), and lower temperatures along the western ice sheet margin, with discrepancies up to -1.5 standard deviation (Fig. 8b), with respect to the original 25rt results. This comparison only identifies non-significant precipitation anomalies (less than 1 standard deviation) located all along the GrIS margin (Fig. 8c), causing a high skill score (0.89).

Furthermore, the comparison between the precipitation anomalies pattern (Fig. 8c) and surface height biases to the 25rt outputs (Fig. 8a) does not lead to a direct relationship between the precipitation simulated by the MAR model and the smooth topography. Indeed, while a locally higher surface height enhances the topographic barrier effect that acts to raise air masses and produce condensation (and hence precipitation during their forced ascent) (Fettweis et al., 2005), a lower surface height induces higher temperatures, which also strengthen the precipitation in Greenland. Given these two processes influencing the simulated precipitation 
Table 4. (a) Skill scores related to the annual anomalies over the 1990-2010 period between the $15 \mathrm{~km}$ resolution MAR outputs (15rt) and the $25 \mathrm{~km}$ resolution (25rt) sublimation and evaporation (SU), run-off of meltwater (RU) and GrIS SMB from the MAR model, without correction (CP0), and corrected with daily gradients implemented on each grid point from the four (CP4), eight (CP8) and twelve (CP12) closest points at $25 \mathrm{~km}$ resolution. (b) The same as (a), but between the $25 \mathrm{rt}$ and $25 \mathrm{st}$ outputs.

\begin{tabular}{llllllllll}
\hline (a) & CP0 & CP4 & CP8 & CP12 & (b) & CP0 & CP4 & CP8 & CP12 \\
\hline SU & 0.70 & 0.72 & 0.72 & 0.73 & SU & 0.60 & 0.81 & 0.85 & 0.85 \\
RU & 0.76 & 0.84 & 0.85 & 0.85 & RU & 0.79 & 0.91 & 0.93 & 0.93 \\
SMB & 0.75 & 0.80 & 0.80 & 0.80 & SMB & 0.83 & 0.88 & 0.90 & 0.90 \\
\hline
\end{tabular}

Table 5. Summary of the main skill scores and annual GrIS SMB results (in brackets) of MAR simulations (e.g. 20rt) interpolated onto higher-resolution GrIS mask (e.g. $15 \mathrm{~km}$ ) and corrected with daily vertical gradients, for the 1990-2010 period.

\begin{tabular}{cccccc}
\hline \multicolumn{5}{c}{ SMB skill scores (and annual SMB results in $\mathrm{Gt} \mathrm{yr}^{-1}$ ) for the GrIS } \\
\hline & $20 \mathrm{rt}$ & $25 \mathrm{rt}$ & $30 \mathrm{rt}$ & $40 \mathrm{ed}$ & $50 \mathrm{ed}$ \\
$15 \mathrm{~km}$ & $0.91(343)$ & $0.80(341)$ & $0.69(357)$ & $0.46(377)$ & $0.33(392)$ \\
$20 \mathrm{~km}$ & & $0.88(321)$ & $0.82(335)$ & $0.54(358)$ & $0.38(372)$ \\
$25 \mathrm{~km}$ & & & $0.90(362)$ & $0.70(382)$ & $0.45(390)$ \\
$30 \mathrm{~km}$ & & & $0.75(352)$ & $0.55(368)$ \\
$40 \mathrm{~km}$ & & & & $0.72(416)$ \\
\hline
\end{tabular}

in conflicting ways, no direct relationship can be extrapolated between the surface height and the precipitation pattern. Due to the high skill score for precipitation (0.89), the precipitation outputs provided by the 25st MAR run can be used without correction in the reconstruction of the SMB field.

Along the western and southern ice sheet margin, where the $50 \mathrm{~km}$ topography is generally too high compared to the $25 \mathrm{~km}$ surface height, the MAR simulation with the $25 \mathrm{st}$ simulation was unable to reproduce the high melting rates because of underestimated temperatures (Fig. 8b), resulting in large negative biases of run-off (locally more than 1.5 standard deviations) compared to the original 25rt outputs (Fig. 8e). After applying the correction to the run-off results, these anomalies were significantly reduced around the ice sheet border (even in the closest vicinity of the GrIS margin) and generally did not exceed 0.5 standard deviations, greatly increasing the related skill score from 0.79 to 0.93 (Fig. 8f). This highlights the close relationship between the melting rates and the steep orography around Greenland, but also proves our method to be effective when correcting the run-off discrepancies induced by a MAR simulation with a smooth topography, compared to the run using the same resolution with the original surface height. Nevertheless, when comparing over the 1990-2010 period the annual amounts of precipitation produced by $25 \mathrm{st}\left(652 \mathrm{Gt} \mathrm{yr}^{-1}\right)$ and $25 \mathrm{rt}\left(649 \mathrm{Gt} \mathrm{yr}^{-1}\right)$, we were unable to prove the coarse topography of the $40-50 \mathrm{~km}$ simulations to be responsible for the MAR model's production of heavier precipitation at low resolution.
Figure $8 \mathrm{~g}-\mathrm{i}$ illustrates the significant overestimation of the SMB on the coarse topography in the western GrIS (with biases locally higher than 1.5 standard deviation) compared to the 25rt run, mainly due to underestimated run-off. By using the precipitation outputs (without correction), corrected run-off and corrected sublimation and evaporation (where the skill score is significantly enhanced from 0.60 to 0.85 ) produced by $25 \mathrm{st}$, the GrIS SMB field can be reconstructed, as in Sect. 6. The SMB interpolation significantly dampened these anomalies, improving the skill score (0.90 instead of 0.83$)$ with respect to the original 25rt MAR results. As regards the daily gradient implementation, it should be noted that the same experiment using the four, eight and twelve closest grid points was carried out, leading to similar results (compiled in Table 4b).

\section{Discussion and conclusion}

In this study, we performed several MAR runs of the GrIS SMB over the period 1990-2010 at different spatial resolutions: $15,20,25,30,40$ and $50 \mathrm{~km}$. Cross sections through the GrIS validated the MAR outputs along the K-transect $\left(67^{\circ} \mathrm{N}\right.$, West Greenland) and revealed a very good match between the MAR results from the higher-resolution runs and the observations. It also appeared that most of the $5 \mathrm{~km}$ ice sheet topography can be reproduced at lower resolutions, but that a model resolution of at least $10-15 \mathrm{~km}$ is needed to resolve the steep slopes in the vicinity of the ice sheet margin.

The outputs (precipitation, run-off of meltwater and SMB) produced by the MAR model running at these different 


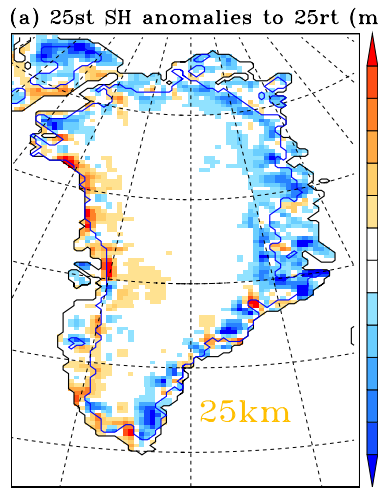

(d) 25rt RU (mmWE $\left.\mathrm{yr}^{-1}\right)$

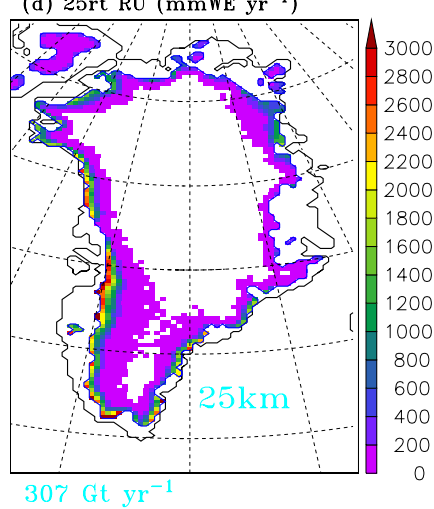

(g) 25rt SMB (mmWE $\left.\mathrm{yr}^{-1}\right)$

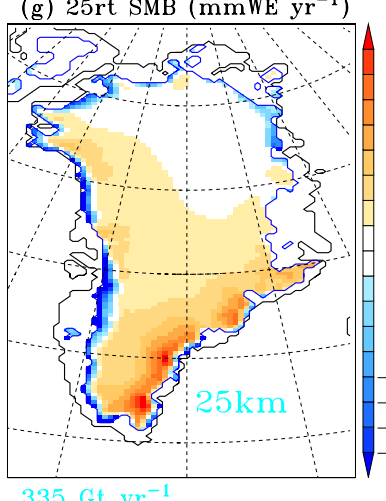

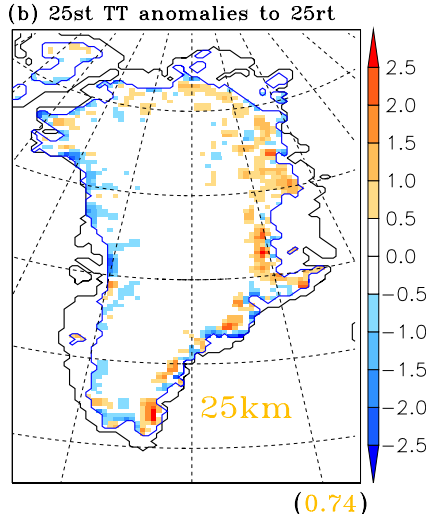

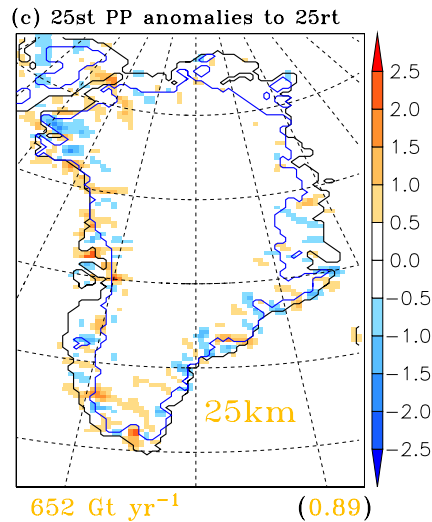

(e) $25 \mathrm{st}$ RU anomalies to $25 \mathrm{rt}$

(f) corr. 25st RU anomalies to $25 \mathrm{rt}$
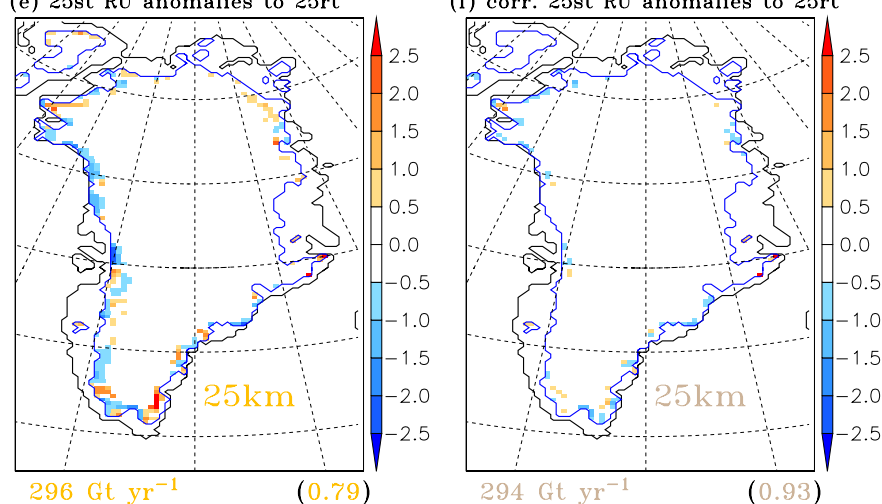

(i) reconstr. 25st SMB anomalies to $25 \mathrm{rt}$
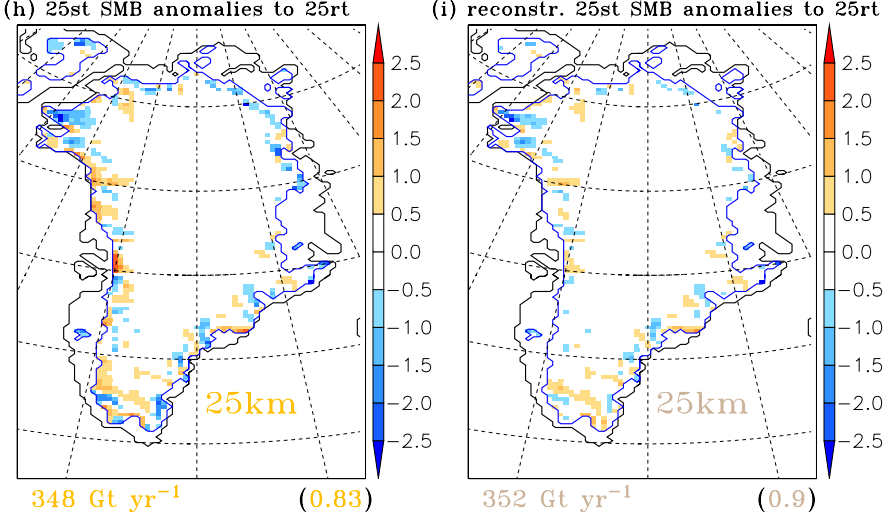

Fig. 8. (a) Surface height anomalies (m) of the $50 \mathrm{~km}$ resolution MAR topography interpolated onto the $25 \mathrm{~km}$ MAR grid (25st), compared to the original $25 \mathrm{~km}$ topography (25rt). (b) Annual near-surface temperature anomalies (in standard deviation) of the $25 \mathrm{st}$ outputs compared to the 25rt outputs, over 1990-2010. On the bottom right side of the view, in brackets, is the skill score of 25st compared to 25rt. (c) The same as (b), but for the annual precipitation anomalies (in standard deviation). On the bottom left side of the view is the annual amount of precipitation over the GrIS from 25st. (d) Annual meltwater run-off ( $\mathrm{mm} \mathrm{WE} \mathrm{yr}^{-1}$ ) provided by $25 \mathrm{rt}$ over the 1990-2010 period. (e) Annual run-off anomalies (in standard deviation) of the 25 st outputs compared to (d). On the bottom right side of the view, in brackets, is the skill score of the 25 st run-off compared to (d). (f) The same as (e), but for the 25 st run-off corrected by daily gradients. (g-i) The same as (d-f), but for the annual SMB (mm WE yr ${ }^{-1}$ ) simulated by the MAR model, and the reconstructed SMB from the corrected 25st outputs.

spatial resolutions were interpolated onto the $15 \mathrm{~km}$ grid, and compared to the $15 \mathrm{~km}$ outputs over the 1990-2010 period. This comparison highlighted increasing biases between the interpolated fields and the $15 \mathrm{~km}$ resolution outputs related to the decrease of the model resolution. Nevertheless, the
20-25 km resolution results were proved to be quite reliable compared with the $15 \mathrm{~km}$ outputs for the GrIS. Moreover, the MAR model produced outputs with an inter-annual variability consistent throughout the whole 1990-2010 period, whatever the spatial resolutions of the MAR run, as well as 
equivalent linear trends. Subsequently, an enhanced SMB interpolation has been satisfactorily tested for improving the comparison between the SMB outputs interpolated onto a higher-resolution ice sheet mask, and the SMB field simulated at this higher resolution. Finally, a comparison was carried out between the $25 \mathrm{~km}$ resolution MAR outputs and results produced by the MAR model running at $25 \mathrm{~km}$ resolution with a coarse topography, with the aim of highlighting the anomalies induced by a smoothed topography on the simulated fields.

This study has also revealed that the MAR model produces heavier precipitation on the GrIS for low-resolution simulations (e.g. $40-50 \mathrm{~km}$ ), while the amount of precipitation remains reasonably consistent within the $15-30 \mathrm{~km}$ resolution runs. The same observation has been made for HadRM3 running at low spatial resolutions (J. L. Bamber and C. Vernon, personal communication, 2011), but these results contradict RACMO, which simulates higher precipitation rates on the GrIS with increasing spatial resolution (Ettema et al., 2009). Therefore, several experiments investigating integration domain size and the topography were performed with MAR in an attempt to explain what increases simulated precipitation at low spatial resolution. However, the extended integration domain specific to the $40-50 \mathrm{~km}$ resolution runs (in order to maintain a sufficient number of pixels between the Greenland and the domain boundaries) is not responsible for the increased precipitation, but on the contrary reduced the MAR precipitation. Furthermore, a comparison between the $25 \mathrm{~km}$ resolution MAR runs implemented either with the $25 \mathrm{~km}$ surface height or the $50 \mathrm{~km}$ topography interpolated onto the $25 \mathrm{~km}$ grid proved that the coarse topography at $40-50 \mathrm{~km}$ resolution does not explain these differences. However, the discrepancies in precipitation estimates by the RCMs are more problematic than their different responses to the spatial resolution. Because snowfall and rainfall represent the main input to the GrIS SMB, further investigations are required to develop a full understanding of what causes heavier precipitation in each RCM. For instance, a detailed comparison between the specific physics of each model should reveal more information about this issue.

In the framework of the ICE2SEA project, the SMB outputs from the MAR model are due to force ice dynamical models with the aim to perform future projections of the GrIS contribution to the global sea-level rise over the next 200 yr. However, the very-high resolution MAR outputs required as forcing fields for this purpose (5-10 km resolution) would need significant computing time, making such simulations unrealistic over a long period. Through this work, it has been shown that "intelligent" interpolation of GrIS SMB outputs from the MAR model at a higher spatial resolution can constitute a satisfactory option in addressing the issue of using SMB results coming directly from MAR runs at this higher resolution without substantial additional computing time. Such experiments are valuable in the process of coupling RCMs with ice dynamical models.
The correction of the interpolated SMB components (especially the run-off of meltwater and the sublimation and evaporation) using vertical gradients of this field, calculated at a daily time scale in the neighbourhood of each grid point, has been proved to be effective for the MAR model and has given satisfactory results for the GrIS SMB reconstructed on a higher-resolution ice sheet mask. Moreover, this method has highlighted that a maximal resolution YY km of less than twice the desired higher resolution $\mathrm{XX} \mathrm{km}$ is required to obtain reliable interpolated SMB results at this higher resolution XX km. It also appears from this study that the anomalies of precipitation outputs interpolated at a higher resolution cannot be significantly reduced by vertical gradients, because precipitation is a non-linear function of the topography.

From the comparison of the MAR outputs with observations along the K-transect, it is clear that the $15 \mathrm{~km}$ spatial resolution is not high enough to resolve the topography and SMB in the closest vicinity of the GrIS margin. Therefore, it is necessary to perform MAR simulations at a higher spatial resolution than $15 \mathrm{~km}$, e.g. $5-10 \mathrm{~km}$, to obtain further GrIS SMB results including the ice-sheet margins which can be compared with the MAR outputs coming from simulations at $15-50 \mathrm{~km}$ resolution.

This work has shown that smoothed topography affects the outputs simulated by the MAR model, and that the enhanced SMB interpolation is able to significantly reduce the anomalies generated by such a coarse topography, compared to the MAR simulation with the original topography. As regards the increasing present day mass loss of the GrIS and the future warmer climate projected in the Arctic that would enhance the melting in Greenland, the related surface height changes of the ice sheet would be of particular interest due to the topography feedbacks on the temperature, run-off of meltwater, etc. Therefore, further endeavours of this type should be set up to develop a full understanding of the behaviours of the MAR model in response to, for example, the raising or lowering of the whole GrIS surface height by $100 \mathrm{~m}$. In a more general sense, response of the RCMs to this kind of stimulus is still relatively unknown.

As the SMB interpolation presented in this work is not based on a statistical approach and is completely independent of the investigated field, it would be possible to carry out an investigation of different spatial resolutions and an enhanced SMB interpolation using GrIS outputs provided by other RCMs, with the aim of testing its reliability. Moreover, this could highlight differences in the dependency of a field to the topography within these RCMs. Indeed, what has been discovered for the MAR model might not hold true for another RCM (e.g. as the RCMs sensitivity to the simulated precipitation varies according to the spatial resolutions). Such studies would lead to a better knowledge of the GrIS SMB modelling. 
Supplementary material related to this article is available online at: http://www.the-cryosphere.net/6/695/ 2012/tc-6-695-2012-supplement.pdf.

Acknowledgements. Bruno Franco is a research fellow of the Belgian National Fund for Scientific Research. This work was partly supported by funding from the ICE2SEA Programme from the European Union 7th Framework Programme. We would like to thank two anonymous reviewers for their constructive comments. Finally, the authors also want to thank Cate Chapman for her precious spelling check in this manuscript.

Edited by: E. Hanna

\section{References}

Bamber, J. L., Ekholm, S., and Krabill, W.: A new, high-resolution digital elevation model of Greenland fully validated with airborne laser altimeter data, J. Geophys. Res., 106, 6733-6745, 2001a.

Bamber, J. L., Layberry, R. L., and Gogineni, S. P.: A new ice thickness and bed data set for the Greenland ice sheet 1. Measurement, data reduction, and errors, J. Geophys. Res., 106, 33773-33780, 2001b.

Box, J. E. and Cohen, A. E.: Upper-air temperatures around Greenland: 1964-2005, Geophys. Res. Lett., 33, L12706, doi:10.1029/2006GL025723, 2006.

Box, J. E., Bromwich, D. H., Veenhuis, B. A., Bai, L.-E., Stroeve, J. C., Rogers, J. C., Steffen, K., Haran, T., and Wang, S.H.: Greenland ice sheet surface mass balance variability (19882004) from calibrated polar MM5 output, J. Climate, 19, 27832800, 2006.

Box, J. E., Cappelen, J., Decker, D., Fettweis, X., Mote, T., Tedesco, M., and van de Wal, R. S. W.: Greenland, in: Arctic Report Card 2010, available at: http://www.arctic.noaa.gov/ reportcard (last access: 14 January 2012), 2010.

Brun, E., David, P., Sudul, M., and Brunot, G.: A numerical model to simulate snowcover stratigraphy for operational avalanche forecasting, J. Glaciol., 38, 13-22, 1992.

Connolley, W. M. and Bracegirdle, T. J.: An Antarctic assessment of IPCC AR4 coupled models, Geophys. Res. Lett., 34, L22505, doi:10.1029/2007GL031648, 2007.

De Ridder, K. and Gallée, H.: Land surface-induced regional climate change in Southern Israel, J. Appl. Meteorol., 37, 14701485,1998

Dethloff, K., Schwager, M., Christensen, J. H., Kiilsholm, S., Rinke, A., Dorn, W., Jung-Rothenhäusler, F., Fischer, H., Kipfstuhl, S., and Miller, H.: Recent Greenland accumulation estimated from regional model simulations and ice core analysis, J. Climate, 15, 2821-2832, 2002.

Ettema, J., van den Broeke, M. R., van Meijgaard, E., van de Berg, W. J., Bamber, J. L., Box, J. E., and Bales, R. C.: Higher surface mass balance of the Greenland ice sheet revealed by highresolution climate modeling, Geophys. Res. Lett., 36, L12501, doi:10.1029/2009GL038110, 2009.

Fettweis, X.: Reconstruction of the 1979-2006 Greenland ice sheet surface mass balance using the regional climate model MAR, The Cryosphere, 1, 21-40, doi:10.5194/tc-1-21-2007, 2007.
Fettweis, X., Gallée, H., Lefebre, L., and van Ypersele, J.-P.: Greenland surface mass balance simulated by a regional climat model and comparison with satellite derived data in 1990-1991, Clim. Dynam., 24, 623-640, doi:10.1007/s00382-005-0010-y, 2005.

Fettweis, X., van Ypersele, J.-P., Gallée, H., Lefebre, F., and Lefebvre, W.: The 1979-2005 Greenland ice sheet melt extent from passive microwave data using an improved version of the melt retrieval XPGR algorithm, Geophys. Res. Lett., 34, L05502, doi:10.1029/2006GL028787, 2007.

Fettweis, X., Hanna, E., Gallée, H., Huybrechts, P., and Erpicum, M.: Estimation of the Greenland ice sheet surface mass balance for the 20th and 21st centuries, The Cryosphere, 2, 117-129, doi:10.5194/tc-2-117-2008, 2008

Fettweis, X., Tedesco, M., van den Broeke, M., and Ettema, J.: Melting trends over the Greenland ice sheet (1958-2009) from spaceborne microwave data and regional climate models, The Cryosphere, 5, 359-375, doi:10.5194/tc-5-359-2011, $2011 \mathrm{a}$.

Fettweis, X., Belleflamme, A., Erpicum, M., Franco, B., and Nicolay, S.: Estimation of the Sea Level Rise by 2100 Resulting from Changes in the Surface Mass Balance of the Greenland Ice Sheet, in: Climate Change - Geophysical Foundations and Ecological Effects, edited by: Blanco, J. and Kheradmand, H., Intech, Croatia, 503-520, 2011b.

Gallée, H. and Schayes, G.: Development of a three-dimensional meso- $\gamma$ primitive equations model, Mon. Weather Rev., 122, 671-685, 1994.

Gallée, H., Guyomarc'h, G., and Brun, E.: Impact of the snow drift on the Antarctic ice sheet surface mass balance: possible sensitivity to snow-surface properties, Bound.-Lay. Meteorol., 99, 1-19, 2001.

Hall, D. K., Williams, R. S., Luthcke, S. B., and Digirolamo, N. E.: Greenland ice sheet surface temperature, melt and mass loss: 2000-2006, J. Glaciol., 54, 81-93, 2008.

Hanna, E., Huybrechts, P., Janssens, I., Cappelen, J., Steffen, K., and Stephens, A.: Runoff and mass balance of the Greenland ice sheet: 1958-2003, J. Geophys. Res., 110, D13108, doi:10.1029/2004JD005641, 2005.

Hanna, E., Huybrechts, P., Steffen, K., Cappelen, J., Huff, R., Shuman, C., Irvine-Fynn, T., Wise, S., and Griffiths, M.: Increased runoff from melt from the Greenland Ice Sheet: a response to global warming, J. Climate, 21, 331-341, 2008.

Helsen, M. M., van de Wal, R. S. W., van den Broeke, M. R., van de Berg, W. J., and Oerlemans, J.: Coupling of climate models and ice sheet models by surface mass balance gradients: application to the Greenland Ice Sheet, The Cryosphere, 6, 255-272, doi:10.5194/tc-6-255-2012, 2012.

Howat, I. M., Joughin, I., Fahnestock, B. E., Smith, T. A., and Cambos, T. A.: Synchronous retreat and acceleration of southeast Greenland outlet glaciers 2000-2006: ice dynamics and coupling to climate, J. Glaciol., 54, 646-660, 2008.

Huybrechts, P.: The present evolution of the Greenland ice sheet: an assessment by modelling, Global Planet. Change, 9, 39-51, 1994.

Lefebre, F., Gallée, H., van Ypersele, J., and Greuell, W.: Modeling of snow and ice melt at ETH-camp (west Greenland) a study of surface albedo, J. Geophys. Res., 108, 4231, doi:10.1029/2001JD001160, 2003.

Lefebre, F., Fettweis, X., Gallée, H., van Ypersele, J., Marbaix, P., Greuell, W., and Calanca, P.: Evaluation of a high-resolution re- 
gional climate simulation over Greenland, Clim. Dynam., 25, 99-116, doi:10.1007/s00382-005-0005-8, 2005.

Lemke, P., Ren, J., Alley, R. B., Allison, I., Carrasco, J., Flato, G., Fujii, Y., Kaser, G., Mote, P., Thomas, R. H., and Zhang, T.: Observations: Changes in Snow, Ice and Frozen Ground, in: Climate Change 2007: The Physical Science Basis, Contribution of Working Group I to the Fourth Assessment Report of the Intergovernmental Panel on Climate Change, edited by: Solomon, S., Qin, D., Manning, M., Chen, Z., Marquis, M., Averyt, K. B., Tignor, M., and Miller, H. L., Cambridge University Press, Cambridge, UK and New York, NY, USA, 2007.

Meehl, G. A., Stocker, T. F., Collins, W. D., Friedlingstein, P., Gaye, A. T., Gregory, J. M., Kitoh, A., Knutti, R., Murphy, J. M., Noda, A., Raper, S. C. B., Watterson, I. G., Weaver, A. J., Zhao, Z. C.: Global climate projections, in: Climate change 2007: The Physical Science Basis, Contribution of Working Group I to the Fourth Assessment Report of the Intergovernmental Panel on Climate Change, edited by: Solomon, S., Qin, D., Manning, M., Chen, Z., Marquis, M., Averyt, K. B., Tignor, M., Miller, H. L., Cambridge University Press, Cambridge, UK and New York, NY, USA, 2007.

Mote, T. L.: Estimation of runoff rates, mass balance, and elevation changes on the Greenland ice sheet from passive microwave observations, J. Geophys. Res., 108, 4056, doi:10.1029/2001JD002032, 2003.

Ritz, C., Fabre, A., and Letréguilly, A.: Sensitivity of a Greenland ice sheet model to ice flow and ablation parameters: consequences for the evolution through the last climatic cycle, Clim. Dynam., 13, 11-24, 1997.

Robinson, A., Calov, R., and Ganopolski, A.: An efficient regional energy-moisture balance model for simulation of the Greenland Ice Sheet response to climate change, The Cryosphere, 4, 129144, doi:10.5194/tc-4-129-2010, 2010.
Stendel, M., Christensen, J. H., and Petersen, D.: Arctic climate and climate change with a focus on Greenland, Adv. Ecol. Res., 40, 13-43, doi:10.1016/S0065-2504(07)00002-5, 2008.

Tedesco, M., Serreze, M., and Fettweis, X.: Diagnosing the extreme surface melt event over southwestern Greenland in 2007, The Cryosphere, 2, 159-166, doi:10.5194/tc-2-159-2008, 2008.

Tedesco, M., Fettweis, X., van den Broeke, M., van de Wal, R., Smeets, P., van de Berg, W. J., Serreze, M., and Box, J.: The role of albedo and accumulation in the 2010 melting record in Greenland, Environ. Res. Lett., 6, 014005, doi:10.1088/17489326/6/1/014005, 2011.

Van de Wal, R. S. W.: Processes of buildup and retreat of the Greenland ice sheet, J. Geophys. Res., 104, 3899-3906, 1999.

Van de Wal, R. S. W., Greuell, W., van den Broeke, M. R., Reijmer, C. H., and Oerlemans, J.: Surface mass-balance observations and automatic weather station data along a transect near Kangerlussuaq, West Greenland, Ann. Glaciol., 42, 311-316, 2005.

Van den Broeke, M. R., Bamber, J., Ettema, J., Rignot, E., Schrama, E., van de Berg, W. J., van Meijgaard, E., Velicogna, I., and Wouters, B.: Partitioning recent Greenland mass loss, Science, 326, 984-986, 2009.

Vizcaíno, M., Mikolajewicz, U., Jungclaus, J., and Schurgers, G.: Climate modification by future ice sheet changes and consequences for ice sheet mass balance, Clim. Dynam., 34, 301-324, doi:10.1007/s00382-009-0591-y, 2010.

Wouters, B., Chambers, D., and Schrama, E. J. O.: GRACE observes small-scale mass loss in Greenland, Geophys. Res. Lett., 35, L20501, doi:10.1029/2008GL034816, 2008. 